\title{
Dynamic nuclear polarisation enhanced
}

\section{${ }^{14} \mathrm{~N}$ overtone MAS NMR spectroscopy}

\author{
Aaron J. Rossini, ${ }^{a}$ Lyndon Emsley ${ }^{\mathrm{a}}$ and Luke A. O’Dell ${ }^{\mathrm{b} *}$,
}

${ }^{a}$ Centre de RMN à Trés Hauts Champs, Institut de Sciences Analytiques, Université de Lyon

(CNRS/ENS Lyon/UCB Lyon 1), 69100 Villeurbanne, France

bInstitute for Frontier Materials, Deakin University, Waurn Ponds Campus, Geelong, Victoria 3220,

Australia

*Corresponding author: luke.odell@deakin.edu.au

\begin{abstract}
Dynamic nuclear polarisation (DNP) has been used to obtain magic angle spinning ${ }^{14} \mathrm{~N}^{\text {OT }}$ (nitrogen-14 overtone) solid-state NMR spectra from several model amino acids, with both direct and indirect observation of the ${ }^{14} \mathrm{~N}^{\text {OT }}$ signal. The crystalline solids were impregnated with biradical solutions of organic liquids that do not dissolve the crystalline phase. The bulk phase was then polarized via ${ }^{1} \mathrm{H}$ spin diffusion from the highly-polarized surface ${ }^{1} \mathrm{H}$ nuclei, resulting in ${ }^{1} \mathrm{H}$ DNP signal enhancements of around two orders of magnitude. Cross polarisation from ${ }^{1} \mathrm{H}$ nuclei directly to the ${ }^{14} \mathrm{~N}$ overtone transition is demonstrated under magic angle spinning, using a standard pulse sequence with a relatively short contact time (on the order of $100 \mu$ s). This method can be used to acquire ${ }^{14} \mathrm{~N}$ overtone MAS powder patterns that match closely with simulated line shapes, allowing isotropic chemical shifts and quadrupolar parameters to be measured. DNP enhancement also allows the rapid acquisition of $2 \mathrm{D}{ }^{14} \mathrm{~N}^{\text {OT }}$ heteronuclear correlation spectra from natural abundance powder samples. ${ }^{1} \mathrm{H}_{-}{ }^{14} \mathrm{~N}^{\text {OT }} \mathrm{HETCOR}$ and ${ }^{13} \mathrm{C}_{-}{ }^{14} \mathrm{~N}^{\text {OT }}$ HMQC pulse sequences were used to observe all single-bond $\mathrm{H}-\mathrm{N}$ and $\mathrm{C}-\mathrm{N}$ correlations in histidine hydrochloride monohydrate, with the spectra obtained in a matter of hours. Due to the high natural abundance of the ${ }^{14} \mathrm{~N}$ isotope $(99.6 \%)$ and the advantages of observing the overtone transition, these methods provide an attractive route to the observation of $\mathrm{C}-\mathrm{N}$ correlations from samples at natural isotopic abundance and enable the high resolution measurement of ${ }^{14} \mathrm{~N}$ chemical shifts and quadrupolar interaction parameters.
\end{abstract}




\section{Introduction}

Solid-state nuclear magnetic resonance (NMR) studies of nitrogen usually target the spin I $=1 / 2{ }^{15} \mathrm{~N}$ isotope, but this nucleus has both a low resonance frequency and an extremely low natural abundance $(0.37 \%)$. Such studies therefore generally require either isotopic enrichment or very long experiment times to achieve a useful signal to noise ratio $(S / N)$. Since the natural abundance of ${ }^{13} \mathrm{C}$ is also very low (1.07\%), only one $\mathrm{C}-\mathrm{N}$ pair in around 25,000 will contain both of these isotopes, so even with the excellent sensitivity afforded by modern NMR techniques and hardware, the observation of ${ }^{13} \mathrm{C}-{ }^{15} \mathrm{~N}$ correlations at natural abundance remains a challenge.

The ${ }^{14} \mathrm{~N}$ nucleus (99.63\% abundance) provides a potential alternative, but poses its own unique challenges due to its integer spin number $(I=1)$ [1]. Unlike half-integer spin quadrupolar nuclei, ${ }^{14} \mathrm{~N}$ lacks a central transition and both of its fundamental $(\Delta m=1)$ transitions experience very large anisotropic broadening due to the first-order quadrupolar coupling, resulting in powder patterns that typically span many $\mathrm{MHz}$. While such broadly dispersed signals can be observed using strategies such as highly stable magic angle spinning (MAS) [2] or frequency-stepped acquisition [3], they are inherently limited in resolution and these approaches are therefore restricted to samples featuring only one or two distinct nitrogen environments [4]. The indirect observation of ${ }^{14} \mathrm{~N}$ using HMQC [5-7] or similar pulse sequences [8] provides an alternative approach that can improve both sensitivity and resolution.

Due to the large quadrupolar couplings experienced by ${ }^{14} \mathrm{~N}$, the overtone $(\Delta m=2)$ transition is weakly allowed, and its direct observation is possible. This transition is unaffected by the first-order quadrupolar interaction and so exhibits far narrower spectral ranges and peak widths. The concept of overtone NMR spectroscopy has been established for many decades $[9,10]$ but it was only recently combined with MAS [11,12], which provides further improvements in resolution by partially averaging the second-order quadrupolar interaction as well as removing other sources of broadening such as chemical shift anisotropy. ${ }^{14} \mathrm{~N}$ overtone $\left({ }^{14} \mathrm{~N}^{\mathrm{OT}}\right)$ MAS NMR therefore allows well-resolved ${ }^{14} \mathrm{~N}$ peaks to be obtained directly from powder samples. The main limitation of this method is its low sensitivity, with the overtone transition providing only a small fraction of the signal attainable from the fundamental transitions. Very recently, several authors have investigated the possibility of observing these overtone signals indirectly via more amenable nuclei such as ${ }^{1} \mathrm{H}$, and this approach shows much promise $[13,14]$. In this contribution, we explore the possibility of using dynamic nuclear polarisation (DNP) to enhance directly and indirectly detected ${ }^{14} \mathrm{~N}^{\text {OT }}$ signals. 
In high-field MAS DNP experiments, the much larger polarisation of unpaired electrons is transferred to nearby nuclear spins, potentially providing signal boosts of several orders of magnitude $[15,16]$. Typically, the analyte is dissolved or suspended in a glassy solution with a stable biradical polarizing agent [17]. Solid-state MAS NMR experiments are then performed at cryogenic temperatures $(<110 \mathrm{~K}$ ) on frozen samples with continuous microwave irradiation to drive the DNP mechanism. Low temperatures are critical to increase the proton and electron relaxation times and obtain large DNP enhancements (up to a factor of several hundred at $9.4 \mathrm{~T}$ [18]). Recently, it has been demonstrated that DNP can enhance the polarisation of protons at the surface of materials that have been impregnated with minimal volumes of bi-radical solutions [1921]. It has also been shown that such impregnation DNP (iDNP) methods can be applied to ordinary micro-crystalline solids impregnated with organic liquids that do not dissolve the crystalline phase [22]. For impregnated solids with long ${ }^{1} \mathrm{H} \mathrm{T}_{1}$ relaxation times, and which contain sufficient proton density, spin diffusion can transport enhanced ${ }^{1} \mathrm{H}$ polarisation from the ${ }^{1} \mathrm{H}$ nuclei at the surface over $\mu \mathrm{m}$ distances into the bulk crystalline phase, after which cross polarisation can be used to transfer the enhanced polarisation to another nucleus such as ${ }^{13} \mathrm{C}$ [22-24]. Recent studies have already applied CP pulse sequences to transfer DNP-enhanced ${ }^{1} \mathrm{H}$ polarisation to the central transitions of half-integer quadrupolar nuclei such as ${ }^{17} \mathrm{O}[25]$ and ${ }^{27} \mathrm{Al}$ [26], while DNP enhancement in the indirect detection of the ${ }^{14} \mathrm{~N}$ fundamental transitions has also been explored using ${ }^{13} \mathrm{C}$ labelled samples [27].

Herein, we use this state-of-the-art approach to demonstrate that cross polarisation from ${ }^{1} \mathrm{H}$ nuclei directly to the ${ }^{14} \mathrm{~N}$ overtone transition is possible under MAS conditions, and results in high quality powder patterns that can be accurately simulated to extract ${ }^{14} \mathrm{~N}$ isotropic chemical shifts and quadrupolar parameters. Furthermore, we show that DNP enhancements can allow ${ }^{1} \mathrm{H}-$ ${ }^{14} \mathrm{~N}^{\text {OT }}$ and ${ }^{13} \mathrm{C}_{-}{ }^{14} \mathrm{~N}^{\text {OT }}$ correlation spectra to be obtained from natural abundance samples in a matter of hours, providing an attractive method for observing C-N correlations from unlabelled samples.

\section{Experimental details}

\section{2a. Sample preparation}

Natural abundance samples of glycine, glycylglycine and L-histidine hydrochloride monohydrate (histidine $\bullet \mathrm{HCl} \bullet \mathrm{H}_{2} \mathrm{O}$ ) were purchased from Sigma Aldrich and used without further purification. Each sample was finely ground by hand using a mortar and pestle for around 15 minutes to reduce the grain size of the crystalline solids [23]. About $50 \mathrm{mg}$ of ground solid was then impregnated with approximately $15 \mu \mathrm{L}$ of a $15 \mathrm{mM}$ solution of TEKPol [18] in (94:6) 
tetrachloroethane (TCE)/methanol- $d_{4}$. Samples were packed into $3.2 \mathrm{~mm}$ outer diameter sapphire MAS NMR rotors. The small amount of methanol- $d_{4}$ was included to improve the glass formation of the TCE solution at the particle surface, and the sample was ejected and re-inserted into the cold NMR probe several times until the ${ }^{13} \mathrm{C}$ signal from the TCE showed a smoother peak shape (i.e., corresponding to a more disordered, glassy solvent) [18]. These two precautions make the DNP enhancement more robust and reproducible.

\section{2b. NMR}

Impregnation DNP (iDNP) experiments were carried out at 9.4 T using a Bruker Avance III $400 \mathrm{MHz}$ DNP spectrometer [28] and a $3.2 \mathrm{~mm}$ triple-resonance MAS probe configured for ${ }^{1} \mathrm{H}-{ }^{13} \mathrm{C}-$ ${ }^{14} \mathrm{~N}^{\text {OT}}$. The ${ }^{14} \mathrm{~N}^{\text {ОT }}$ frequency at this field strength is approximately $57.6 \mathrm{MHz}$. The sample temperature was around $107 \mathrm{~K}$ and microwave irradiation was generated using a $263 \mathrm{GHz}$ gyrotron with an estimated output power of $4 \mathrm{~W}$. A MAS rate of $10 \mathrm{kHz}$ was used unless otherwise specified. Certain other (non-DNP) spectra were obtained at $11.7 \mathrm{~T}$ using a Bruker Avance III $500 \mathrm{MHz}$ spectrometer and a $4.0 \mathrm{~mm}$ triple-resonance MAS probe configured for ${ }^{1} \mathrm{H}-{ }^{13} \mathrm{C}-$ ${ }^{14} \mathrm{~N}^{\mathrm{OT}}$ (see figure captions for details).

A basic cross polarisation pulse sequence (Fig 1a) was used to acquire ${ }^{13} \mathrm{C}$ and ${ }^{14} \mathrm{~N}^{\mathrm{OT}} \mathrm{MAS}$ spectra with a ramped contact pulse on the ${ }^{1} \mathrm{H}$ channel $[29,30]$. In all cases SPINAL-64 ${ }^{1} \mathrm{H}$ heteronuclear decoupling was applied with a $100 \mathrm{kHz}$ RF field [31]. Unless otherwise specified, the contact time for the ${ }^{14} \mathrm{~N}^{\text {OT }}$ CPMAS was $125 \mu \mathrm{s}$ with the ${ }^{1} \mathrm{H}$ power linearly varied from $\mathrm{v}_{1}\left({ }^{1} \mathrm{H}\right) \approx 20$ to $39 \mathrm{kHz}$ and a constant amplitude ${ }^{14} \mathrm{~N}^{\mathrm{OT}}$ pulse with RF power corresponding to $\mathrm{v}_{1}\left({ }^{2} \mathrm{H}\right)=83 \mathrm{kHz}[12]$. The ${ }^{2} \mathrm{H}$ pulse calibrations were performed separately with DNP using a frozen solution of $16 \mathrm{mM}$ AMUPol [32] dissolved in DMSO- $d_{6} / \mathrm{D}_{2} \mathrm{O} / \mathrm{H}_{2} \mathrm{O}(60: 36: 4)$. All ${ }^{14} \mathrm{~N}^{\text {OT }}$ pulses were applied onresonance with the $+2 \omega_{\text {r }}$ overtone sideband unless otherwise stated. The ${ }^{14} \mathrm{~N}^{\text {OT }}$ spectra are referenced against twice the (fundamental) ${ }^{14} \mathrm{~N}$ frequency obtained from solid $\mathrm{NH}_{4} \mathrm{Cl}$ at $0 \mathrm{kHz}$. A $\mathrm{kHz}$ scale (rather than ppm) is conventionally used for overtone NMR spectra, and is also more practical given the MAS rate dependence of the peak positions. While ${ }^{14} \mathrm{~N}^{\mathrm{OT}} \mathrm{NMR}$ spectra can be obtained from powder samples spinning at any orientation, the magic angle will generally provide the best sensitivity and resolution through the averaging of chemical shielding anisotropy and dipolar coupling effects.

Since no ${ }^{14} \mathrm{~N}^{\text {OT }}$ signal could be observed at $107 \mathrm{~K}$ without the DNP enhancement, the CP enhancement levels for the bulk crystalline samples were determined indirectly using ${ }^{13} \mathrm{C}$ CPMAS spectra acquired with $10 \mathrm{~s}$ recycle delays, and are denoted by the symbol $\varepsilon_{\mathrm{c} c P}$ (defined as the ratio 
of the signal intensities of the ${ }^{13} \mathrm{C}$ CPMAS spectra acquired with and without microwave irradiation, and with all other experimental parameters the same). These ${ }^{13} \mathrm{C}$ spectra are provided in the supporting information. The values of $\varepsilon_{C} \mathrm{CP}$ provide a good estimate of the ${ }^{14} \mathrm{~N}^{\mathrm{OT}} \mathrm{CP}$ DNP enhancements since the same network of protons (with the same level of polarisation enhancement) are involved in the ${ }^{14} \mathrm{~N}^{\mathrm{OT}}$ and ${ }^{13} \mathrm{C}$ cross polarisation experiments. Since longer recycle delays were generally used for the acquisition of the ${ }^{14} \mathrm{~N}^{\mathrm{OT}}$ CPMAS spectra, the spin diffusion times over which the enhanced surface ${ }^{1} \mathrm{H}$ magnetisation moves into the bulk phase will be different. These $\varepsilon_{C}$ CP values therefore provide only an estimate of the ${ }^{14} \mathrm{~N}^{\text {OT }}$ CP DNP enhancement. We have also compared the ${ }^{14} \mathrm{~N}^{\text {OT }}$ DNP-enhanced CPMAS sensitivity with direct excitation at room temperature, and this is discussed in section 3. Finally, the lack of observable signal in the ${ }^{1} \mathrm{H}^{14} \mathrm{~N}^{\text {OT }} \mathrm{CP}$ spectra acquired without DNP enhancement is consistent with the large $\varepsilon_{\mathrm{C} \mathrm{CP}}(>80)$ measured for ${ }^{13} \mathrm{C}$ for all compounds.

A ${ }^{13} \mathrm{C}_{-14} \mathrm{~N}^{\text {OT }}$ HMQC pulse sequence was used to observe $\mathrm{C}-\mathrm{N}$ correlations at natural abundance (Fig 1b). A similar pulse sequence was recently used to record ${ }^{1} \mathrm{H}_{-}{ }^{14} \mathrm{~N}^{\text {OT }}$ spectra and is discussed in more detail elsewhere $[13,14]$. Two differences here are the addition of the ${ }^{1} \mathrm{H}_{-}{ }^{13} \mathrm{C}$ cross polarisation scheme and the inclusion of the microwaves for the DNP enhancement. ${ }^{14} \mathrm{~N}^{\mathrm{OT}}$ pulse lengths were $200 \mu$ s in length $\left(\mathrm{V}_{1}\left({ }^{2} \mathrm{H}\right) \approx 83 \mathrm{kHz}\right)$ and the recoupling time $(\tau)$ was $7.5 \mathrm{~ms}$. A ${ }^{1} \mathrm{H}-$ ${ }^{14} \mathrm{~N}^{\text {OT }} \mathrm{CP}-\mathrm{HETCOR}$ pulse sequence [33] was also used (Fig $1 \mathrm{c}$ ). During the ${ }^{1} \mathrm{H}$ indirect evolution period $\left(t_{1}\right)$ e-DUMBO- $1_{22}$ homonuclear ${ }^{1} \mathrm{H}$ decoupling was applied with an RF field strength of approximately $100 \mathrm{kHz}$ to improve the resolution in the ${ }^{1} \mathrm{H}$ dimension [34], followed by cross polarisation to the ${ }^{14} \mathrm{~N}^{\text {OT }}$ transition and signal detection. For both of these $2 \mathrm{D}$ experiments the States-TPPI procedure was used for quadrature detection in the indirect dimension. Additional experimental details are provided in the figure captions.

\section{2c. Simulations}

Exact numerical simulations of ${ }^{14} \mathrm{~N}^{\text {OT }}$ MAS powder patterns were carried out using the SpinDynamica software running under Mathematica as described previously [12]. Unless otherwise stated, a very short $(0.1 \mu \mathrm{s})$ excitation pulse was simulated to achieve uniform excitation, and only the $+2 \omega_{\mathrm{r}}$ overtone sidebands are shown. A MAS rate of $70 \mathrm{kHz}$ was simulated to speed up the calculation times and also to fully separate the overtone sidebands. The spectra were subsequently shifted by $-120 \mathrm{kHz}$ to set the $+2 \omega_{\mathrm{r}}$ overtone sideband to the $10 \mathrm{kHz}$ MAS position. The ${ }^{14} \mathrm{~N}$ NMR parameters used in these simulations are provided in Table S1 in the supporting information. The quadrupolar coupling constants $\left(C_{Q}\right)$ and asymmetry parameters $\left(\eta_{Q}\right)$ 
were reported previously for the case of glycine [4] and histidine $\bullet \mathrm{HCl} \bullet \mathrm{H}_{2} \mathrm{O}$ [14], and were calculated for glycylglycine from a crystal structure [35] using the CASTEP software [36]. To match the simulations to the experimental spectra, the isotropic chemical shifts (obtained from ${ }^{15} \mathrm{~N}$ CPMAS spectra) were fixed and the quadrupolar parameters were manually adjusted using the reported or calculated parameters as initial values. It should be noted that due to the isotropic quadrupolar shift, both the $C_{Q}$ and the isotropic chemical shift $\delta_{\text {iso }}$ can affect the position of the ${ }^{14} \mathrm{~N}^{\text {OT }}$ powder patterns, with the $\mathrm{C}_{\mathrm{Q}}$ parameter also varying their width. Since each simulation required several hours of computational time, a reliable estimate of the uncertainties in the $C_{Q}$ and $\eta_{Q}$ values determined this way was not feasible. Faster computational methods [37] should facilitate more straightforward fitting of these spectra and the extraction of all three parameters with greater precision.

\section{Results and discussion}

Glycine is an excellent model system on which to test ${ }^{14} \mathrm{~N}^{\text {OT }}$ MAS NMR experiments. The width of its $+2 \omega_{\text {r }}$ overtone sideband is on the order of a few $\mathrm{kHz}$ at intermediate field strengths, so a MAS rate of $10 \mathrm{kHz}$ is sufficient to fully separate it from the other sidebands [11,12]. Line shape distortions due to the pre-acquisition delay are also minimal. With ${ }^{1} \mathrm{H}$ decoupling applied and a recycle delay of $0.5 \mathrm{~s}$, the signal can typically be observed in a matter of minutes at room temperature using a high power ${ }^{14} \mathrm{~N}^{\text {OT }}$ pulse on the order of $100 \mu \mathrm{s}$ in length and applied directly on resonance with the $+2 \omega_{r}$ sideband [11]. This sideband not only provides far more signal than the other four, but was also recently shown to exhibit faster nutation rates [14]. We have therefore used glycine to test the possibility of cross polarisation from the ${ }^{1} \mathrm{H}$ nuclei directly to the ${ }^{14} \mathrm{~N}$ overtone transition under MAS.

Prior to this work, static ${ }^{14} \mathrm{~N}^{\text {OT }} \mathrm{CP}$ spectra were obtained by cross polarisation from ${ }^{1} \mathrm{H}$ dipolar order using Jeener-Broekaert and adiabatic demagnetisation in the rotating frame (ADRF) pulse sequences $[10,38]$. Such experiments were chosen because the RF powers applied to the two nuclei do not have a strict matching requirement, however they are only suitable for static samples. For CPMAS experiments carried out on spin-1/2 nuclei, the conventional method is to spin lock both nuclei at the Hartmann-Hahn match condition using the pulse sequence shown in

Fig $1 \mathrm{a}$, and to the best of our knowledge no ${ }^{14} \mathrm{~N}^{\text {OT }}$ CPMAS spectrum has yet been reported. The ${ }^{14} \mathrm{~N}^{\text {OT }}$ CPMAS NMR spectrum in Fig $2 \mathrm{a}$ was obtained using this approach at $107 \mathrm{~K}$ and with the ${ }^{1} \mathrm{H}$ magnetisation enhanced using DNP. Due to the reduced effective RF field experienced by the overtone magnetisation, the ${ }^{14} \mathrm{~N}^{\text {OT }}$ contact pulse was set to as high an RF power as safely available 
(corresponding to $\mathrm{v}_{1}\left({ }^{2} \mathrm{H}\right) \approx 83 \mathrm{kHz}$ ). An optimum match condition was then determined by varying the RF power of the ramped ${ }^{1} \mathrm{H}$ contact pulse $[29,30]$, and the most efficient $\mathrm{CP}$ transfer was observed with a maximum ${ }^{1} \mathrm{H}$ RF amplitude of approximately $40 \mathrm{kHz}$ (Fig 3a). At this match condition, a contact time of between 100 and $150 \mu$ s provided the highest ${ }^{14} \mathrm{~N}^{\text {OT }}$ signal intensity (Fig 3c). This is relatively short compared to the contact times of 2 to 3 ms typically required for optimal ${ }^{1} \mathrm{H}$ CP transfer to ${ }^{13} \mathrm{C}$ in fully protonated organic solids [39], and could be due to the inability to spin lock the ${ }^{14} \mathrm{~N}^{\text {OT }}$ magnetisation for an extended period of time. A more detailed investigation into the ${ }^{1} \mathrm{H}$ to ${ }^{14} \mathrm{~N}^{\mathrm{OT}}$ cross polarisation mechanism will be required before the efficiency of these experimental settings can be quantified, but this is beyond the scope of this paper. It is possible that the experimental conditions used here allow only a fraction of the total theoretical CP enhancement to be attained, however the very high level of signal enhancement afforded by DNP allowed a high quality ${ }^{14} \mathrm{~N}^{\text {OT }}$ spectrum to be obtained in just 16 scans (10.7 minutes). Moreover, the shape of the powder pattern matches extremely well with the simulation (Fig 2c), indicating that the polarisation transfer efficiency is similar for all crystallite orientations under these CP conditions. This is important because distortion-free powder patterns enable the accurate measurement of ${ }^{14} \mathrm{~N}$ quadrupolar parameters and isotropic chemical shifts, which are highly sensitive to the structural environment surrounding the nitrogen.

At $9.4 \mathrm{~T},{ }^{14} \mathrm{~N}^{\mathrm{OT}}$ MAS signals will potentially span a frequency range on the order of $100 \mathrm{kHz}$. We therefore tested the CP bandwidth by varying the offset frequency for the ${ }^{14} \mathrm{~N}^{\mathrm{OT}}$ contact pulse, and the ${ }^{14} \mathrm{~N}^{\text {OT }}$ signal was observed at offsets of up to $+25 \mathrm{kHz}$ (Fig 3d), albeit with a significant decrease in intensity. This bandwidth is comparable to ${ }^{1} \mathrm{H}_{-}{ }^{14} \mathrm{~N}^{\mathrm{OT}} \mathrm{CP}$ bandwidths previously reported for static samples [38]. In addition, the CP experiment was repeated with the ${ }^{14} \mathrm{~N}^{\text {OT }}$ contact pulse applied on-resonance with the $+\omega_{r}$ overtone sideband (i.e., at a frequency offset of $-10 \mathrm{kHz}$ ). No visible signal was observed from this sideband (see Fig S3 in the supporting information), which is consistent with our previous unsuccessful attempts to observe it directly [12] and provides further evidence that all overtone sidebands apart from that at $+2 \omega_{r}$ can generally be ignored. The different nutation rates exhibited by the other sidebands [14] would also be expected to result in different CP match conditions for them, further decreasing the likelihood of observing these peaks. This is beneficial since lineshape distortions from sideband overlap are likely to be minimal (vide infra).

A quantitative analysis of the improvement in sensitivity enabled by this iDNP-CP experiment is complicated by several inter-related factors. In the absence of microwave irradiation, no ${ }^{14} \mathrm{~N}^{\text {OT }}$ signal was observed at all (Fig $2 b$ ). The reported DNP enhancement for this 
and subsequent samples was therefore measured indirectly using ${ }^{13} \mathrm{C}$ CPMAS experiments, since the same bath of protons are involved in the ${ }^{13} \mathrm{C}$ and ${ }^{14} \mathrm{~N}^{\text {OT }} \mathrm{CP}$ transfers. In this case, a DNP enhancement of $\varepsilon_{C \mathrm{CP}}=82$ was obtained (Fig S2). We were also unable to observe the ${ }^{14} \mathrm{~N}^{\mathrm{OT}}$ signal at $107 \mathrm{~K}$ using direct excitation, and we attribute this to a significant increase in the ${ }^{14} \mathrm{~N}^{\text {OT }} \mathrm{T}_{1}$ relaxation time at this temperature. Our preliminary efforts to record a room temperature ${ }^{14} \mathrm{~N}^{\text {OT }}$ CPMAS experiment without DNP enhancement have also been unsuccessful. While a DNP enhancement level on the order of 80 is certainly appreciable, the rather long ${ }^{1} \mathrm{H}_{1}$ relaxation time (which ensures that large DNP enhancements are obtained for the bulk phase) imposed a recycle delay of $40 \mathrm{~s}$ for optimal sensitivity in the iDNP-CP experiment. This is 80 times longer than the recycle delay required for direct excitation at room temperature, representing a reduction in sensitivity by a factor of approximately 9. However, we have previously observed that the reduction in sensitivity due to increased longitudinal relaxation times is usually partially offset by the improved Boltzmann polarisation and probe quality factor $[23,40]$.

In a practical sense, the most pertinent sensitivity comparison is between the iDNP-CP experiment and direct excitation of the ${ }^{14} \mathrm{~N}^{\text {OT }}$ transition at room temperature [40]. Such a comparison is shown in Fig 4, with the two spectra obtained from glycine in the same experimental time-frame (5.4 minutes) and using the same sample and hardware. The iDNP-CP spectrum shows a $\mathrm{S} / \mathrm{N}$ over four times higher than that of the room temperature direct excitation experiment, translating to a factor of 16 reduction in experiment time. Clearly this comparison is specific to glycine and will be dependent on several factors that will vary between samples, most importantly the value of $\varepsilon_{\mathrm{C} C P}$ and the ${ }^{1} \mathrm{H}$ and ${ }^{14} \mathrm{~N}^{\text {OT }} \mathrm{T}_{1}$ relaxation times, but it does provide a clear illustration of the potential sensitivity gains enabled by the iDNP-CP approach. We also note a small apparent shift in peak position between the two spectra in Fig 4, which we attribute to the difference in sample temperature.

As has recently been shown, the indirect detection of ${ }^{14} \mathrm{~N}^{\mathrm{OT}}$ signals via more amenable spin-half nuclei such as ${ }^{1} \mathrm{H}$ or ${ }^{13} \mathrm{C}$ can be advantageous in terms of both sensitivity and information content $[13,14]$, and preliminary studies have indicated that the efficiency of the coherence transfer between ${ }^{1} \mathrm{H}$ and the ${ }^{14} \mathrm{~N}^{\mathrm{OT}}$ transition using the $\mathrm{HMQC}$ pulse sequence is comparable to that of the fundamental single-quantum ${ }^{14} \mathrm{~N} \mathrm{HMQC} \mathrm{approach} \mathrm{[13].} \mathrm{DNP} \mathrm{enhancements} \mathrm{have} \mathrm{also}$ previously been obtained in ${ }^{13} \mathrm{C}-{ }^{14} \mathrm{~N}$ (fundamental) $\mathrm{HMQC}$ experiments carried out on ${ }^{13} \mathrm{C}$ labelled samples [27]. Herein we explore the possibility of observing C-N correlations at natural abundance. 
Fig 5a shows a ${ }^{13} \mathrm{C}^{14} \mathrm{~N}^{\text {OT }} \mathrm{HMQC}$ spectrum obtained from a natural abundance sample of glycine with DNP enhancement achieved via the initial cross polarisation from ${ }^{1} \mathrm{H}$ to the ${ }^{13} \mathrm{C}$ nuclei. In this case, a DNP enhancement factor of $\varepsilon_{\mathrm{c} C P}=89$ (obtained from a second sample of glycine) allowed this spectrum to be obtained in just $2.8 \mathrm{~h}$. The high quality ${ }^{14} \mathrm{~N}^{\mathrm{OT}}$ powder pattern shape in this spectrum is noteworthy, since indirectly detected ${ }^{14} \mathrm{~N}$ powder patterns obtained by irradiating the fundamental transitions are often highly distorted [7]. For comparison, HMQC spectra were also obtained without DNP enhancement using a more standard experimental set-up (4 mm MAS probe, room temperature), albeit at a slightly higher magnetic field strength (11.7 T). In this case, a high quality spectrum was obtained from a sample $99 \%$ enriched in ${ }^{13} \mathrm{C}$ at the $\mathrm{C} 2$ position in 50 $\min$ (Fig 5b). For a natural abundance sample however, an acquisition time of $64 \mathrm{~h}$ was required, and the resulting spectrum shows a poor S/N (Fig 5c). Furthermore, no distinguishable features in the ${ }^{14} \mathrm{~N}^{\text {OT }}$ powder pattern can be observed because the poor sensitivity limited the number of $t_{1}$ increments that were acquired. In this light, iDNP methods clearly show considerable potential for obtaining C-N correlation spectra from natural abundance powdered organic solids.

The iDNP-CP experiment was also tested on the dipeptide glycylglycine, which features two distinct nitrogen environments. For this sample a DNP enhancement of $\varepsilon_{\mathrm{c}} \mathrm{CP}=123$ was obtained (Fig S4). The spectrum obtained from the $\mathrm{NH}_{3}$ nitrogen site is shown in Fig 6a, and shows a characteristic second order powder pattern shape with two sharp horns. This shape actually differs somewhat from the "ideal" overtone powder pattern, i.e., that arising from uniform excitation (see Fig S5 in the supporting information). However, by simulating an excitation pulse $125 \mu \mathrm{s}$ in length to model the effects of the finite spin lock period in the CP pulse sequence, the observed line shape is reproduced with high accuracy. The NH nitrogen site in this sample has a much larger quadrupolar interaction and a correspondingly broader ${ }^{14} \mathrm{~N}^{\mathrm{OT}}$ powder pattern, measuring around $20 \mathrm{kHz}$ in width at its base. Despite this, the ${ }^{14} \mathrm{~N}^{\mathrm{OT}}$ DNP-CP spectrum obtained from this site at just $10 \mathrm{kHz}$ MAS shows a good quality powder pattern that matches reasonably well with the simulated line shape (Fig 6c). We attribute this to the much lower relative intensities of the other sidebands and also their different nutation rates which are expected to translate to very different $\mathrm{CP}$ match conditions. This result bodes well for ${ }^{14} \mathrm{~N}$ overtone MAS NMR in general since it demonstrates that the MAS rates do not necessarily have to be faster than the powder pattern widths, thereby allowing larger rotor sizes to be used and boosting the overall sensitivity.

As Fig 3d shows, the CP conditions used in this work can excite a bandwidth on the order of $50 \mathrm{kHz}$ (albeit non-uniformly). In order to verify that multiple sites within this range can indeed be excited in a single experiment, we applied the same pulse sequence to a sample of 
histidine $\bullet \mathrm{HCl} \bullet \mathrm{H}_{2} \mathrm{O}$, which features three distinct nitrogen environments whose ${ }^{14} \mathrm{~N}^{\text {OT }}$ signals span a range of approximately $20 \mathrm{kHz}$ at $9.4 \mathrm{~T}$. For this sample, a large DNP enhancement of $\varepsilon_{\mathrm{c}} \mathrm{cP}=225$ was obtained (Fig S6). The three ${ }^{14} \mathrm{~N}^{\text {OT }}$ signals from this amino acid were recently observed indirectly using a ${ }^{1} \mathrm{H}_{-}{ }^{14} \mathrm{~N}^{\text {OT }} \mathrm{HMQC}$ pulse sequence at $11.7 \mathrm{~T}$ and $62.5 \mathrm{kHz}$ MAS. While this latter experiment resulted in a spectrum of high $\mathrm{S} / \mathrm{N}$ and also provided the ${ }^{1} \mathrm{H}-{ }^{14} \mathrm{~N}$ correlation information, it took approximately $64 \mathrm{~h}$ to acquire [14]. In contrast, Fig 7a shows the iDNP-CP spectrum acquired in just one hour. ${ }^{14} \mathrm{~N}^{\text {OT }}$ powder patterns from all three nitrogen sites are observed and can be simulated to a reasonable level of accuracy (Fig 7 b) despite partial overlap for sites N2 and N3.

Two-dimensional correlation experiments can allow overlapping ${ }^{14} \mathrm{~N}^{\text {OT }}$ signals to be resolved. A high quality ${ }^{1} \mathrm{H}_{-}{ }^{14} \mathrm{~N}^{\mathrm{OT}} \mathrm{CP}$ HETCOR spectrum of histidine $\bullet \mathrm{HCl} \bullet \mathrm{H}_{2} \mathrm{O}$ is shown in Fig $8 \mathrm{~b}$, and was obtained in $8 \mathrm{~h}$. Despite the relatively low MAS rate $(10 \mathrm{kHz})$, a high resolution in the ${ }^{1} \mathrm{H}$ dimension was obtained using e-DUMBO homonuclear ${ }^{1} \mathrm{H}$ decoupling [34] during the evolution period. All three ${ }^{14} \mathrm{~N}^{\text {OT }}$ signals are fully resolved and correlated with the directly bonded ${ }^{1} \mathrm{H}$ nuclei. In contrast to the previously published ${ }^{1} \mathrm{H}^{-}{ }^{14} \mathrm{~N}^{O T} \mathrm{HMQC}$ spectrum mentioned above, this HETCOR spectrum retains distortion-free ${ }^{14} \mathrm{~N}^{\text {OT }}$ powder patterns in the direct dimension. Horizontal slices through these ${ }^{14} \mathrm{~N}^{\text {OT }}$ line shapes are shown to the right of the spectrum in Fig $8 \mathrm{~b}$, and match well with the simulated powder patterns in Fig 7.

Two ${ }^{13} \mathrm{C}^{14} \mathrm{~N}^{\text {OT }} \mathrm{HMQC}$ spectra were also obtained from this natural abundance histidine $\bullet \mathrm{HCl} \bullet \mathrm{H}_{2} \mathrm{O}$ sample, with the ${ }^{14} \mathrm{~N}^{\text {OT }}$ pulses applied at the frequencies of the ring nitrogen signals ( $\mathrm{N} 2$ and $\mathrm{N} 3$ ) and the $\mathrm{NH}_{3}$ nitrogen signal (Figs $8 \mathrm{c}$ and $8 \mathrm{~d}$ respectively). Each spectrum required only $3.8 \mathrm{~h}$ of acquisition time, and all single-bond $\mathrm{C}-\mathrm{N}$ correlations are observed. We note that the use of frequency-swept pulses should allow all of these correlations to be observed in a single experiment by increasing the bandwidth in the ${ }^{14} \mathrm{~N}^{\mathrm{OT}}$ dimension, as has recently been shown [14], but this also comes at the expense of a decreased sensitivity. Given the speed at which the ${ }^{14} \mathrm{~N}^{\mathrm{OT}}$ signals can be observed using these methods, an optimum strategy may be to first obtain the iDNP-CP ${ }^{14} \mathrm{~N}^{\text {OT }}$ spectra directly and subsequently acquire the heteronuclear correlation spectra with the ${ }^{14} \mathrm{~N}^{\mathrm{OT}}$ pulse frequencies optimised for the various nitrogen signals observed.

It is important to note that impregnation DNP methods similar to those described here can also allow natural abundance ${ }^{15} \mathrm{~N}$ spectra to be acquired in relatively short experiment times, as has already been shown [24,41-44]. We therefore obtained DNP-enhanced ${ }^{15} \mathrm{~N}$ CPMAS spectra from the three samples studied, and these are shown in Fig 9. The spectra were obtained at natural abundance with acquisition times of eight minutes, and show high $\mathrm{S} / \mathrm{N}$ ratios (above 50 in 
all cases). Table S2 in the supporting information provides comparisons of the ${ }^{14} \mathrm{~N}^{\text {OT }}$ and ${ }^{15} \mathrm{~N}$ sensitivities for the spectra acquired in this work. While the ${ }^{15} \mathrm{~N}$ DNP experiment certainly offers higher sensitivity and spectral resolution, the ${ }^{14} \mathrm{~N}^{\text {OT }}$ MAS spectra inherently contain more structural information via the quadrupolar interaction parameters. For a thorough characterisation of nitrogen sites, the acquisition of both spectra is ideal, with the isotropic chemical shifts measured by ${ }^{15} \mathrm{~N}$ providing restraints for the fitting of the ${ }^{14} \mathrm{~N}^{\text {OT }}$ powder patterns, as we have demonstrated herein.

Crucially, while modern DNP methods will certainly make natural abundance ${ }^{13} \mathrm{C}-{ }^{15} \mathrm{~N}$ correlation experiments more feasible, the very low natural abundances of both ${ }^{13} \mathrm{C}$ and ${ }^{15} \mathrm{~N}$ isotopes and the high abundance of the ${ }^{14} \mathrm{~N}$ isotope mean that ${ }^{13} \mathrm{C}-{ }^{14} \mathrm{~N}$ correlation experiments will provide superior sensitivity. For example, we determined the ${ }^{13} \mathrm{C}^{-14} \mathrm{~N}^{\mathrm{OT}} \mathrm{HMQC}$ filter efficiency to be about $2.8 \%$ for glycylglycine (Figue S7), and this could potentially be further improved using dipolar recoupling for ${ }^{13} \mathrm{C}_{-}{ }^{14} \mathrm{~N}^{\text {OT }}$ coherence transfer or more fully optimised ${ }^{14} \mathrm{~N}^{\text {OT }}$ excitation pulses. Due to the low abundance of ${ }^{15} \mathrm{~N}$, the maximum efficiency obtainable for ${ }^{13} \mathrm{C}-{ }^{15} \mathrm{~N}$ coherence transfer is $0.37 \%$ and in practice the efficiencies will be lower than this due to imperfections in the coherence transfer. Therefore, natural abundance ${ }^{13} \mathrm{C}_{-}-{ }^{14} \mathrm{~N}^{\mathrm{OT}}$ (or ${ }^{13} \mathrm{C}_{-}{ }^{14} \mathrm{~N}$ fundamental) correlation experiments provide a sensitivity that is at least one order of magnitude higher than ${ }^{13} \mathrm{C}-{ }^{15} \mathrm{~N}$ correlation experiments, and so should remain the preferred method for obtaining C-N correlations.

Finally, while we have focused primarily on DNP polarisation of ${ }^{1} \mathrm{H}$ nuclei and subsequent $\mathrm{CP}$ transfer to the ${ }^{14} \mathrm{~N}$ overtone transition, recent studies have demonstrated the direct polarisation of the quadrupolar nucleus ${ }^{17} \mathrm{O}[25,45]$. The possibility of directly polarizing the ${ }^{14} \mathrm{~N}^{\mathrm{OT}}$ transition would certainly be of interest, and would overcome any potential issues relating to the $\mathrm{CP}$ transfer step. Indirect observation of the ${ }^{14} \mathrm{~N}$ double quantum transition using methods first developed by Ernst et al. [46,47] may also be worth revisiting.

\section{Conclusions}

We have used the impregnation DNP approach [19-21] to obtain ${ }^{14} \mathrm{~N}^{\mathrm{OT}} \mathrm{NMR}$ signal enhancement levels of around two orders of magnitude and have shown for the first time that cross polarisation from ${ }^{1} \mathrm{H}$ nuclei directly to the ${ }^{14} \mathrm{~N}$ overtone transition is possible under MAS conditions. A basic CPMAS pulse sequence with contact times on the order of $100 \mu \mathrm{s}$ enabled multiple resolved ${ }^{14} \mathrm{~N}$ overtone powder patterns to be observed in a matter of minutes on a $9.4 \mathrm{~T}$ DNP spectrometer. Importantly, the powder patterns acquired match well with simulated ${ }^{14} \mathrm{~N}^{\text {OT }}$ 
MAS line shapes, allowing for the accurate measurement of ${ }^{14} \mathrm{~N}$ quadrupolar parameters and isotropic chemical shifts. A more detailed investigation into the ${ }^{1} \mathrm{H}-{ }^{14} \mathrm{~N}^{\text {OT }}$ cross polarisation mechanism could potentially allow these experiments to be further optimised, providing additional gains in sensitivity.

We have also shown that $2 \mathrm{D}{ }^{1} \mathrm{H}-{ }^{14} \mathrm{~N}^{\text {OT }}$ and ${ }^{13} \mathrm{C}-{ }^{14} \mathrm{~N}^{\text {OT }}$ correlation spectra can be acquired from natural abundance powder samples in a matter of hours. This was demonstrated using an unlabelled sample of histidine hydrochloride monohydrate, for which all the single-bond $\mathrm{H}-\mathrm{N}$ and $\mathrm{C}-\mathrm{N}$ correlations were observed. The HETCOR experiment also enabled two overlapping ${ }^{14} \mathrm{~N}^{\mathrm{OT}}$ signals to be resolved, while maintaining accurate ${ }^{14} \mathrm{~N}^{\text {OT }}$ line shapes.

The ability to acquire natural abundance C-N correlation spectra in relatively short timescales will greatly aid resonance assignment for NMR crystallography of polymorphic phases, and we anticipate that these methods will be applicable to a wide range of interesting organic materials such as pure active pharmaceutical ingredients, formulated pharmaceuticals, metalorganic frameworks and polymers, and micro- and meso-porous materials. We are currently pursuing further experiments along these lines.

\section{Acknowledgements}

Dr. David Gajan is thanked for assistance in setting up the DNP experiments, and Dr. Andreas Brinkmann (National Research Council, Canada) is acknowledged for writing the SpinDynamica code to simulate overtone MAS spectra (SpinDynamica is available at spindynamica.soton.ac.uk). We thank Prof. Paul Tordo, Dr. Olivier Ouari, Dr. Gilles Casano and Claire Sauvée (Aix-Marseille University) for providing the TEKPol and AMUPol biradicals. We acknowledge financial support from EQUIPEX Contract ANR-10-EQPX-47-01 and ERC Advanced Grant No. 320860. The Australian Research Council is also acknowledged for funding Deakin University's Magnetic Resonance Facility through LIEF grant LE11010014.

\section{References}

[1] L.A. O’Dell, Prog. Nucl. Magn. Reson. Spec. 59 (2011) 295-318

[2] H.J. Jakobsen, H. Bildsøe, J. Skibsted and T. Giavani, J. Am. Chem. Soc. 123 (2001) 50985099

[3] E.A. Hill and J.P. Yesinowski, J. Am. Chem. Soc. 118 (1996) 6798-6799

[4] L.A. O'Dell, R.W. Schurko, K.J. Harris, J. Autschbach and C.I. Ratcliffe, J. Am. Chem. Soc. 133 (2011) 527-546 
[5] Z. Gan, J. Am. Chem. Soc. 128 (2006) 6040-6041

[6] S. Cavadini, A. Lupulescu, S. Antonijevic and G. Bodenhausen, J. Am. Chem. Soc. 128 (2006) 7706-7707

[7] S. Cavadini, Prog. Nucl. Magn. Reson. Spec. 56 (2010) 46-77

[8] J.A. Jarvis, I.M. Haies, P.T.F. Williamson and M. Carravetta, Phys. Chem. Chem. Phys 15 (2013) 7613-7620

[9] M. Bloom and M.A. LeGros, Can. J. Phys. 64 (1986) 1522-1528

[10] R. Tycko and S.J. Opella, J. Chem. Phys. 86 (1987) 1761-1774

[11] L.A. O'Dell and C.I. Ratcliffe, Chem. Phys. Lett. 514 (2011) 168-173

[12] L.A. O'Dell and A. Brinkmann, J. Chem. Phys. 138 (2013) 064201

[13] Y. Nishiyama, M. Malon, Z. Gan, Y. Endo and T. Nemoto, J. Magn. Reson. 230 (2013) 160164

[14] L.A. O’Dell, R. He and J. Pandohee, Cryst. Eng. Comm. 15 (2013) 8657-8667

[15] T. Maly, G.T. Debelouchina, V.S. Bajaj, K.-N. Hu, C.-G. Joo, M.L. Mak-Jurkauskas, J.R. Sirigiri, P.C.A. van der Wel, J. Herzfeld, R.J. Temkin and R.G. Griffin, J. Chem. Phys. 128 (2008) 052211

[16] Q.N. Ni, E. Daviso, T.V. Can, E. Markhasin, S.K. Jawla, T.M. Swager, R.J. Temkin, J. Herzfeld and R.G. Griffin, Acc. Chem. Res. 46 (2013) 1933-1941

[17] C. Song, K.-N. Hu, C.-G. Joo, T.M. Swager and R.G. Griffin, J. Am. Chem. Soc. 128 (2006) $11385-11390$

[18] A. Zagdoun, G. Casano, O. Ouari, M. Schwarzwälder, A.J. Rossini, F. Aussenac, M. Yulikov, G. Jeschke, C. Copéret, A. Lesage, P. Tordo and L. Emsley, J. Am. Chem. Soc. 135 (2013) 1279012797

[19] A. Lesage, M. Lelli, D. Gajan, M.A. Caporini, V. Vitzthum, P. Miéville, J. Alauzun, A. Roussey, C. Thieuleux, A. Mehdi, G. Bodenhausen, C. Copéret and L. Emsley, J. Am. Chem. Soc. 132 (2010) 15459-15461

[20] A.J. Rossini, A. Zagdoun, M. Lelli, A. Lesage, C. Copéret and L. Emsley, Acc. Chem. Res. 46 (2013) 1942-1951

[21] M. Lelli, D. Gajan, A. Lesage, M.A. Caporini, V. Vitzthum, P. Miéville, F. Héroguel, F. Rascón, A. Roussey, C. Thieuluex, M. Boualleg, L. Veyre, G. Bodenhausen, C. Copéret and L. Emsley, J. Am. Chem. Soc. 133 (2011) 2104-2107

[22] A.J. Rossini, A. Zagdoun, F. Hegner, M. Schwarzwälder, D. Gajan, C. Copéret, A. Lesage and L. Emsley, J. Am. Chem. Soc. 134 (2012) 16899-16908 
[23] P.C.A. van der Wel, K.-N. Hu, J. Lewandowski and R.G. Griffin, J. Am. Chem. Soc. 128 (2006) 10840-10846

[24] A.J. Rossini, C.M. Widdifield, A. Zagdoun, M. Lelli, M. Schwarzwälder, C. Copéret, A. Lesage and L. Emsley, J. Am. Chem. Soc. 136 (2014) 2324-2334

[25] F. Blanc, L. Sperrin, D.A. Jefferson, S. Pawsey, M. Rosay, C.P. Grey, J. Am. Chem. Soc. 135 (2013) 2975-2978

[26] V. Vitzthum, P. Miéville, D. Carnevale, M.A. Caporini, D. Gajan, C. Copéret, M. Lelli, A. Zagdoun, A.J. Rossini, A. Lesage, L. Emsley and G. Bodenhausen, Chem. Commun. 48 (2012) 1988-1990

[27] V. Vitzthum, M.A. Caporini and G. Bodenhausen, J. Magn. Reson. 205 (2010) 177-179

[28] M. Rosay, L. Tometich, S. Pawsey, R. Bader, R. Schauwecker, M. Blank, P.M. Borchard, S.R. Cauffman, K.L. Felch, R.T. Weber, R.J. Temkin, R.G. Griffin and W.E. Maas, Phys. Chem. Chem. Phys. 12 (2010) 5850-5860

[29] G. Metz, X.L. Wu and S.O. Smith, J. Magn. Reson. A 110 (1994) 219-227

[30] O. Peersen, X. Wu, I. Kustanovich and S. Smith, J. Magn. Reson. A, 104 (1993) 334-339

[31] B.M. Fung, A.K. Khitrin and K. Ermolaev, J. Magn. Reson. 142 (2000) 97-101

[32] C. Sauvée, M. Rosay, G. Casano, F. Aussenac, R.T. Weber, O. Ouari, and P. Tordo, Angew. Chem. Int. Ed. 52 (2013) 10858-10861

[33] J.E. Roberts, S. Vega and R.G. Griffin, J. Am. Chem. Soc. 106 (1984) 2506-2512

[34] B. Elena, G. de Paepe and L. Emsley, Chem. Phys. Lett. 398 (2004) 532-538

[35] A.B. Biswas, E.W. Hughes, B.D. Sharma and J.N. Wilson, Acta Cryst. B 24 (1968) 40-50

[36] S.J. Clark, M.D. Segall, C.J. Pickard, P.J. Hasnip, M.J. Probert, K. Refson and M.C. Payne, Z. Kristallogr. 220 (2005) 567-570

[37] H.J. Hogben, M. Krzystyniak, G.T.P. Charnock, P.J. Hore and I. Kuprov, J. Magn. Reson. 208 (2011) 179-194

[38] D.-K. Lee and A. Ramamoorthy, Chem. Phys. Lett. 286 (1998) 398-402

[39] L.B. Alemany, D.M. Grant, R.J. Pugmire, T.D. Alger and K.W. Zilm, J. Am. Chem. Soc. 105 (1983) 2133-2141

[40] A.J. Rossini, A. Zagdoun, M. Lelli, D. Gajan, F. Rascón, M. Rosay, W.E. Maas, C. Copéret, A. Lesage and L. Emsley, Chem. Sci. 3 (2012) 108-115

[41] J.Z. Hu, M.S. Solum, R.A. Wind, B.L. Nilsson, M.A. Peterson, R.J. Pugmire and D.M. Grant, J. Phys. Chem. A 104 (2000) 4413-4420 
[42] A.J. Rossini, A. Zagdoun, M. Lelli, J. Canivet, S. Aguado, O. Ouari, P. Tordo, M. Rosay, W.E. Maas, C. Copéret, D. Farrusseng, L. Emsley and A. Lesage, Angew. Chem. Int. Ed. 124 (2012) 127-131

[43] A. Zagdoun, G. Casano, O. Ouari, G. Lapadula, A.J. Rossini, M. Lelli, M. Baffert, D. Gajan, L. Veyre, W.E. Maas, M. Rosay, R.T. Weber, C. Thieuleux, C. Copéret, A. Lesage, P. Tordo and L. Emsley, J. Am. Chem. Soc. 134 (2012) 2284-2291

[44] F. Blanc, S.Y. Chong, T.O. McDonald, D.J. Adams, S. Pawsey, M.A. Caporini and A.I. Cooper, J. Am. Chem. Soc. 135 (2013) 15290-15293

[45] V.K. Michaelis, B. Corzilius, A.A. Smith and R.G. Griffin, J. Phys. Chem. B 117 (2013) 1489414906

[46] H. Fuess, D. Hohlwein and S.A. Mason, Acta Cryst. B 33 (1977) 654-659

[47] P. Brunner, M. Reinhold and R.R. Ernst, J. Chem. Phys. 73 (1980) 1086-1094

[48] M. Reinhold, P. Brunner and R.R. Ernst, J. Chem. Phys. 74 (1981) 184-188 
Figures

(a)

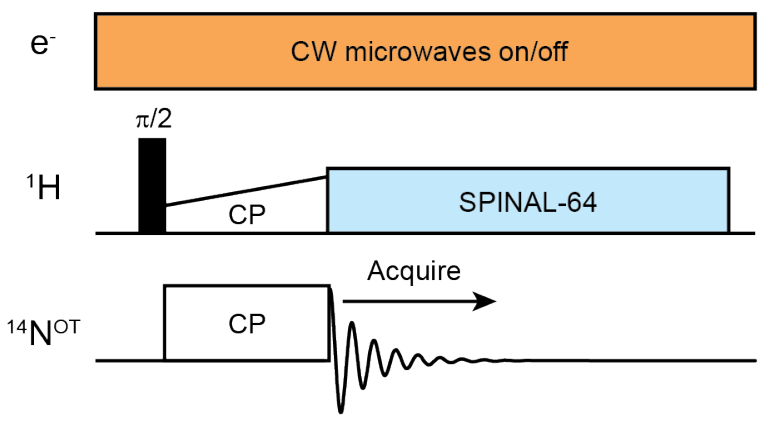

(b)
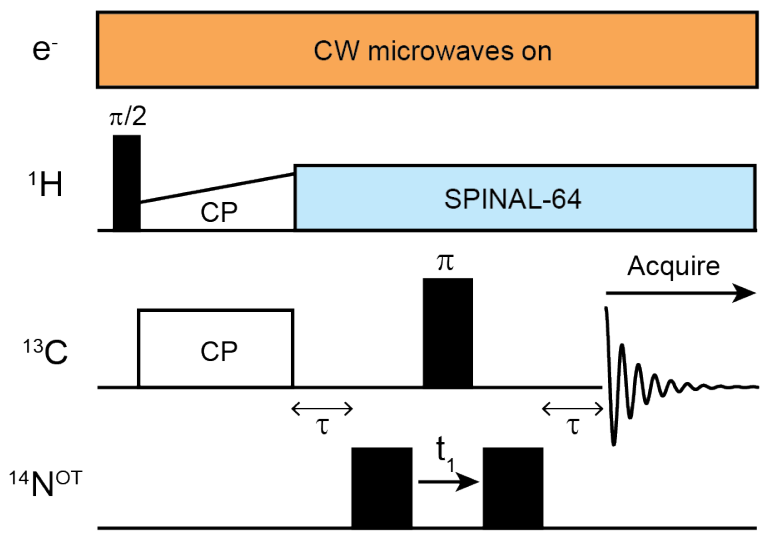

(c)

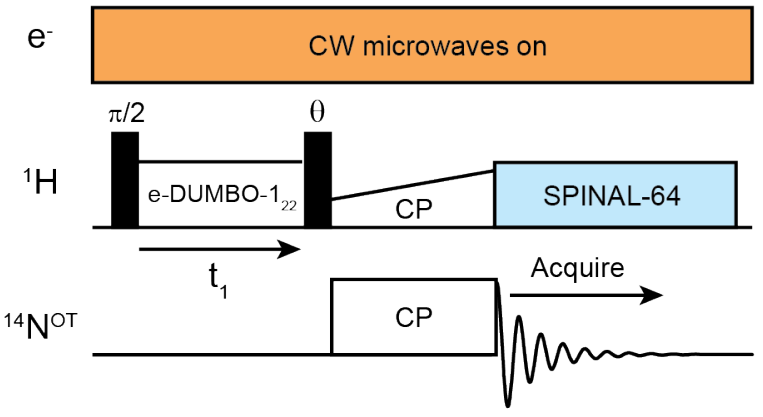

Figure 1 - The various pulse sequences used in this work, each with continuous-wave microwave irradiation to achieve the DNP enhancement. (a) Cross polarisation with a ramped contact pulse on the ${ }^{1} \mathrm{H}$ channel, see section 3 for a discussion of the parameters used. (b) ${ }^{13} \mathrm{C}^{-14} \mathrm{~N}^{\mathrm{OT}} \mathrm{HMQC}$ with cross polarisation from ${ }^{1} \mathrm{H}$. (c) ${ }^{1} \mathrm{H}_{-}{ }^{14} \mathrm{~N}^{\mathrm{OT}} \mathrm{HETCOR}$ with homonuclear e-DUMBO- $1_{22}$ decoupling [34] applied during the $t_{1}$ evolution period. 


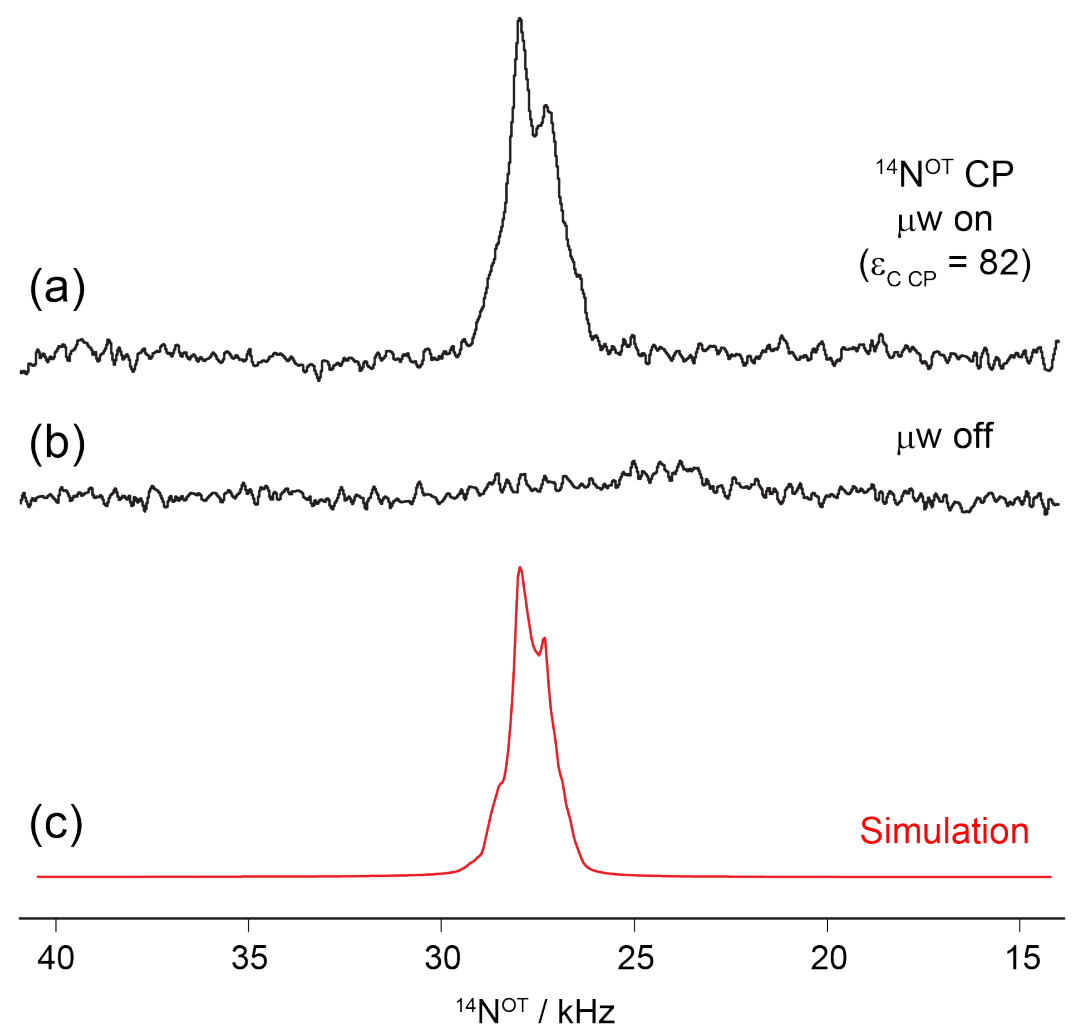

Figure $2-$ (a) ${ }^{14} \mathrm{~N}^{\text {OT }}$ spectrum obtained from glycine at $107 \mathrm{~K}, 9.4 \mathrm{~T}$ and $10 \mathrm{kHz}$ MAS using DNPenhanced cross polarisation from the ${ }^{1} \mathrm{H}$ nuclei. 16 scans were acquired with a recycle delay of 40 $\mathrm{s}$ and a CP contact time of $125 \mu \mathrm{s}$. The DNP enhancement was determined indirectly using a ${ }^{13} \mathrm{C}$ CP MAS experiments to measure $\varepsilon_{\mathrm{C}} \mathrm{CP}$. (b) A spectrum obtained under the same conditions but without microwaves. (c) Simulated ${ }^{14} \mathrm{~N}^{\text {OT }}$ spectrum. 

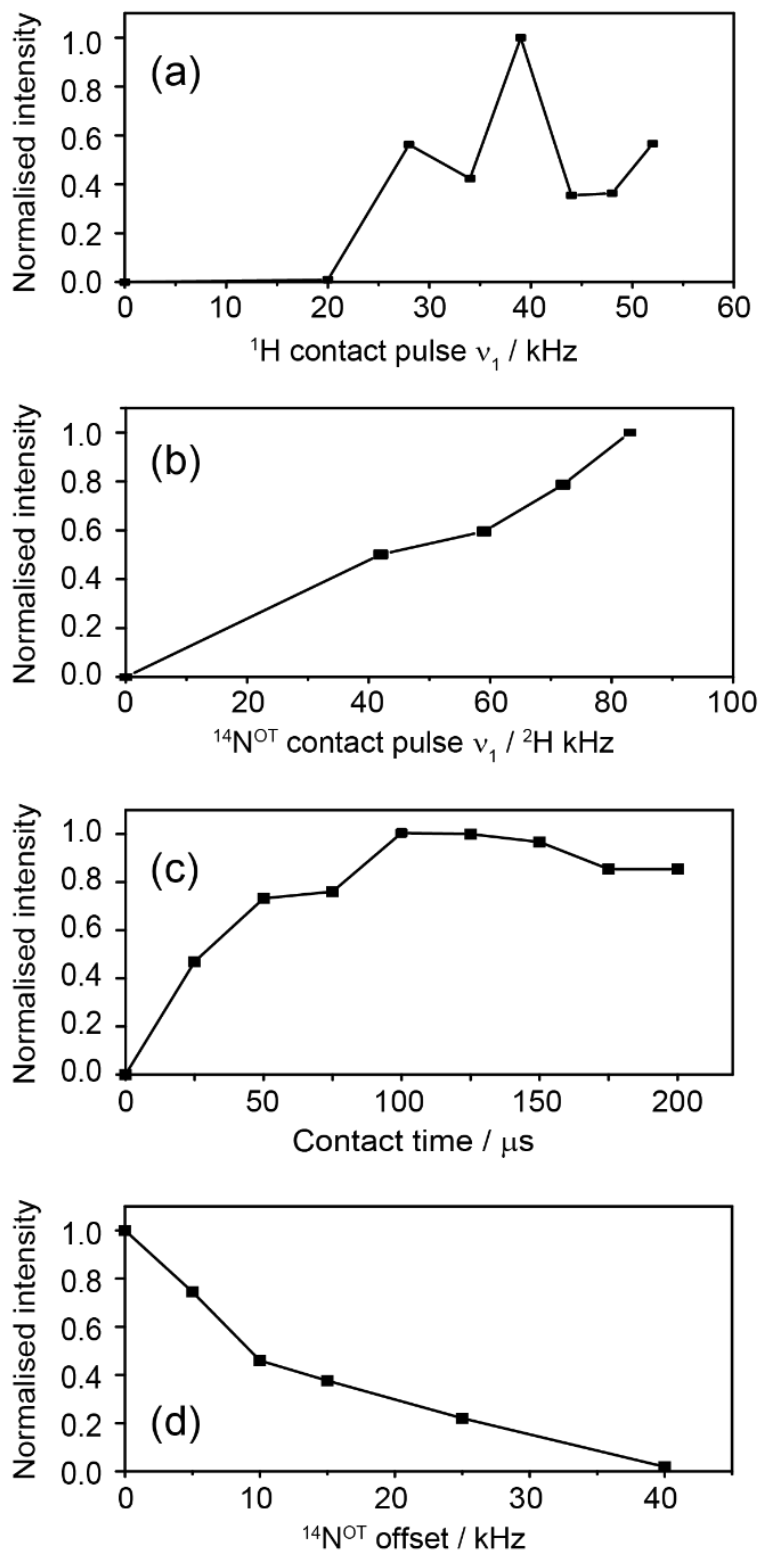

Figure 3 - Relative DNP-enhanced ${ }^{14} \mathrm{~N}^{\text {OT }}$ signal intensities obtained using the pulse sequence in Fig 1, versus (a) the ${ }^{1} \mathrm{H}$ contact pulse amplitude (maximum value for a pulse shape ramped from $50 \%$ to $100 \%)$, (b) the ${ }^{14} \mathrm{~N}^{\text {OT }}$ contact pulse amplitude as measured indirectly using ${ }^{2} \mathrm{H}$ [12] while the ${ }^{1} \mathrm{H}$ RF amplitude was held at $39 \mathrm{kHz}$, (c) the contact time (with optimal CP conditions), and (d) the ${ }^{14} \mathrm{~N}^{\mathrm{OT}}$ pulse frequency offset with a $125 \mu$ s contact pulse and optimized CP conditions. 


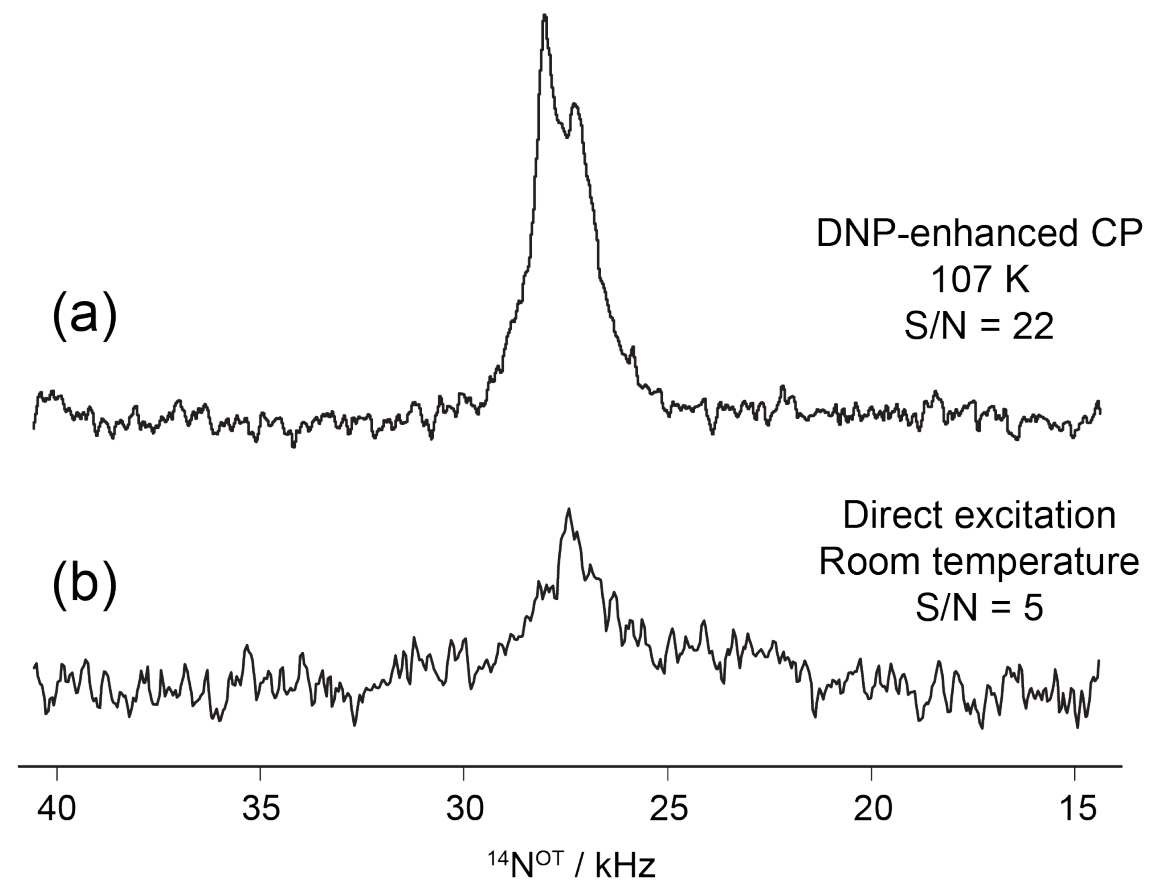

Figure $4-{ }^{14} \mathrm{~N}^{\text {OT }}$ NMR spectra obtained from glycine at $9.4 \mathrm{~T}$ and $10 \mathrm{kHz}$ MAS using (a) DNPenhanced cross polarisation at $107 \mathrm{~K}$ with a recycle delay of $40 \mathrm{~s}$ and 8 scans acquired, and (b) direct excitation at room temperature on the same sample and spectrometer, using a $100 \mu \mathrm{s}$ excitation pulse, a recycle delay of $0.5 \mathrm{~s}$ and 648 scans acquired. 

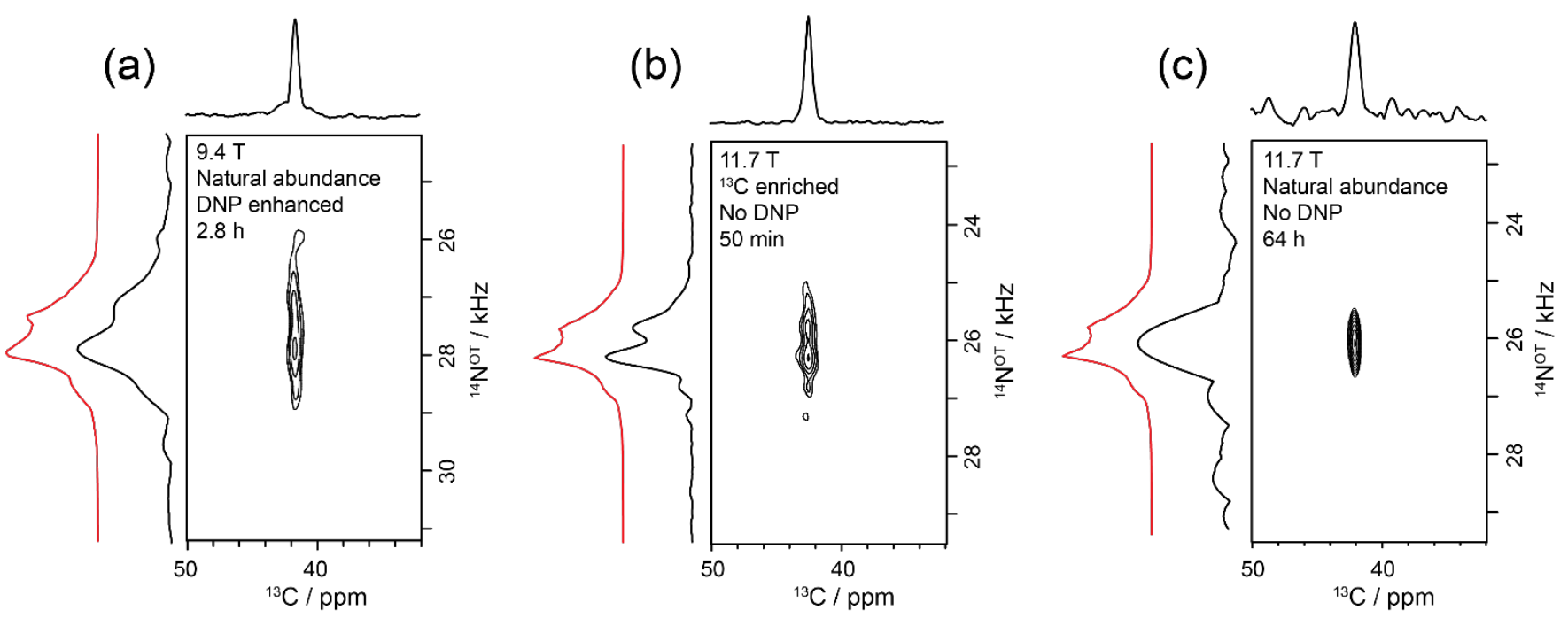

Figure 5 - Comparison of ${ }^{13} \mathrm{C}-{ }^{14} \mathrm{~N}^{\mathrm{OT}} \mathrm{HMQC}$ spectra obtained from powder samples of glycine under different conditions. Spectrum (a) was obtained in $2.8 \mathrm{~h}$ from a natural isotopic abundance sample at 9.4 T, $10 \mathrm{kHz}$ MAS and $107 \mathrm{~K}$ with DNP enhancement (16 scans per slice, 64 slices, $10 \mathrm{~s}$ recycle delay, $\varepsilon_{\mathrm{C} C P}=89$ ). Spectrum (b) was obtained in $50 \mathrm{~min}$ from a sample fully enriched in ${ }^{13} \mathrm{C}$ at site $\mathrm{C} 2$ at $11.7 \mathrm{~T}, 10 \mathrm{kHz}$ MAS and at room temperature (64 scans per slice, 48 slices, $1 \mathrm{~s}$ recycle delay). Spectrum (c) was obtained in $64 \mathrm{~h}$ from a natural abundance sample at $11.7 \mathrm{~T}, 10 \mathrm{kHz}$ MAS and at room temperature (16384 scans per slice, 14 slices, $1 \mathrm{~s}$ recycle delay). Simulated ${ }^{14} \mathrm{~N}^{\text {OT }}$ powder patterns are shown to the left of each spectrum, in red. 

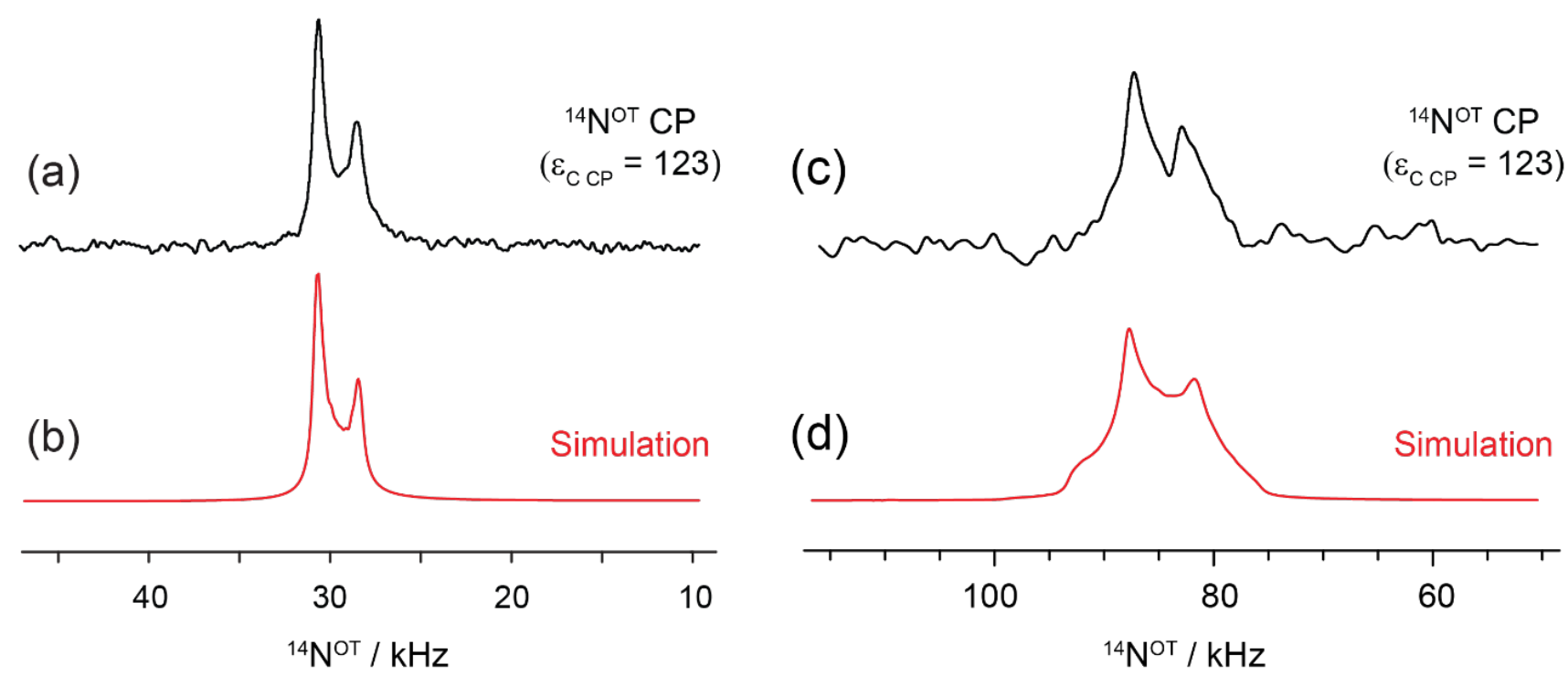

Figure $6-{ }^{14} \mathrm{~N}^{\text {OT }}$ spectra obtained from glycylglycine at $107 \mathrm{~K}, 10 \mathrm{kHz}$ MAS and 9.4 T using DNPenhanced cross polarisation from the ${ }^{1} \mathrm{H}$ nuclei, with a CP contact time of $125 \mu$ s and the ${ }^{14} \mathrm{~N}^{\text {OT }}$ contact pulse applied on resonance with (a) the $\mathrm{NH}_{3}$ peak and (c) the $\mathrm{NH}$ peak. In both cases, 32 scans were acquired with a recycle delay of $60 \mathrm{~s}$. For (c), a slightly lower maximum ${ }^{1} \mathrm{H}$ nutation frequency of $33 \mathrm{kHz}$ during the ${ }^{1} \mathrm{H}$ contact pulse was employed. Simulated ${ }^{14} \mathrm{~N}^{\text {OT }}$ powder patterns are also shown in (b) and (d). 


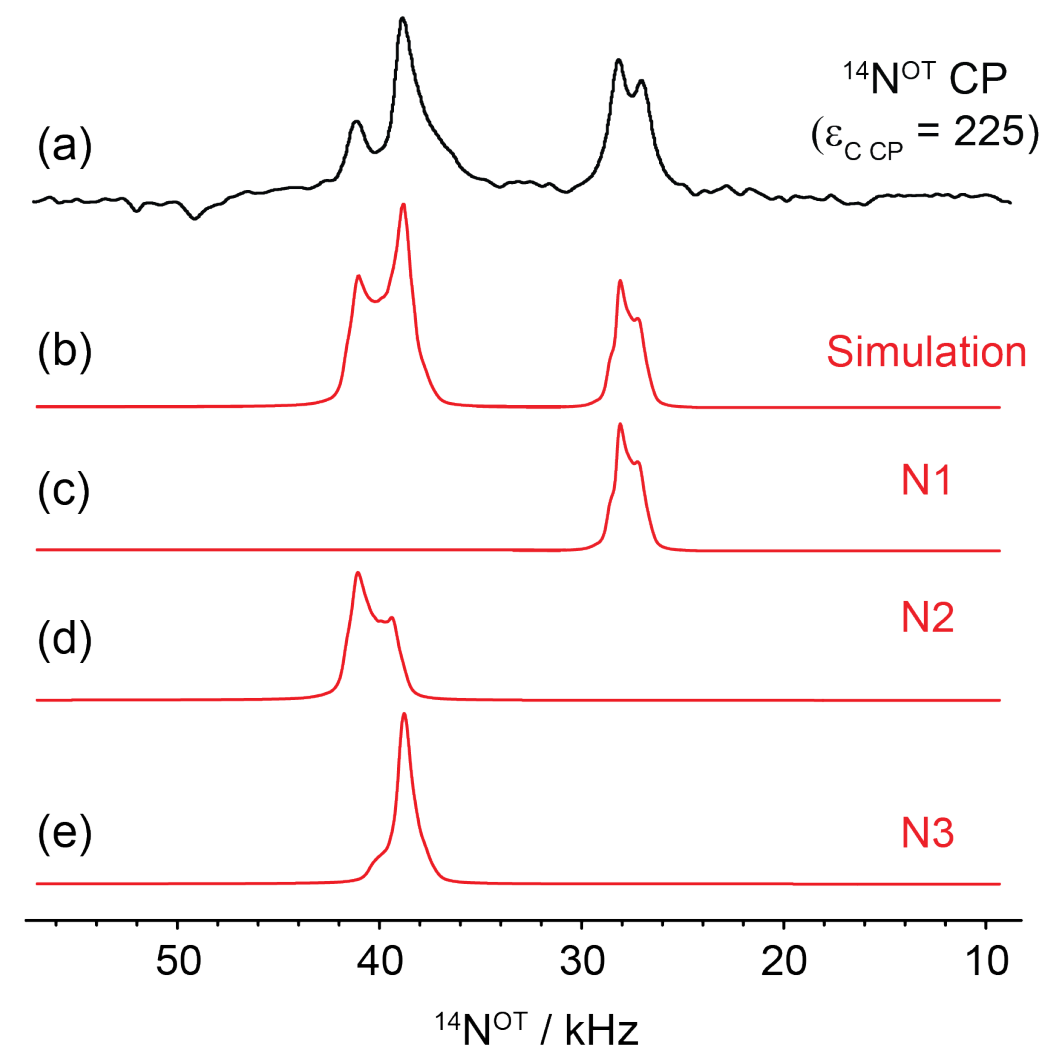

Figure $7-$ (a) ${ }^{14} \mathrm{~N}^{\text {OT }}$ spectrum obtained from histidine $\bullet \mathrm{HCl} \bullet \mathrm{H}_{2} \mathrm{O}$ at $107 \mathrm{~K}, 9.4 \mathrm{~T}$ and $10 \mathrm{kHz} \mathrm{MAS}$ using DNP-enhanced cross polarisation from the ${ }^{1} \mathrm{H}$ nuclei. 64 scans were acquired with a recycle delay of $60 \mathrm{~s}$. The ${ }^{14} \mathrm{~N}^{\text {OT }}$ contact pulse RF frequency was set to approximately $35 \mathrm{kHz}$. (b) Simulation of all three sites, with the individual sites shown in (c), (d) and (e). 
(a)

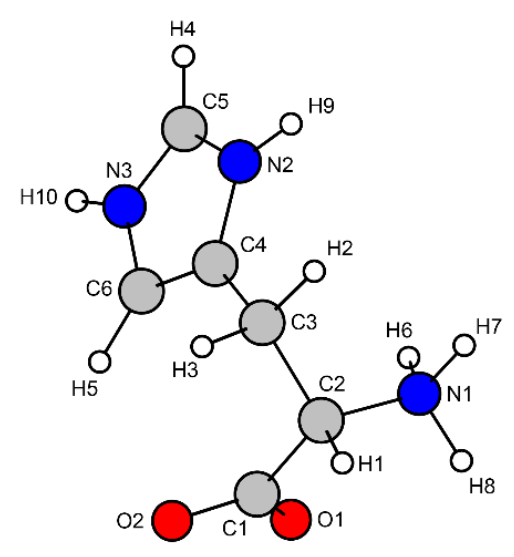

(b)

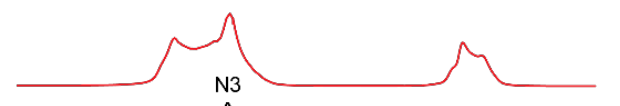

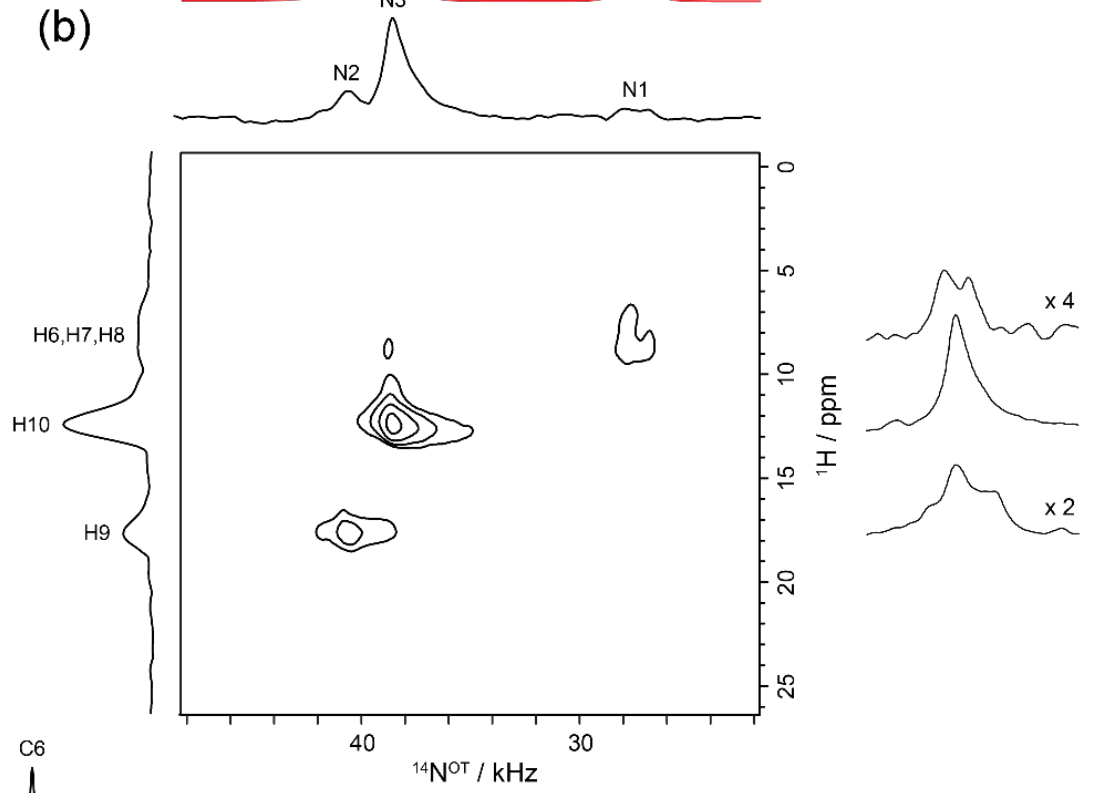

(c)
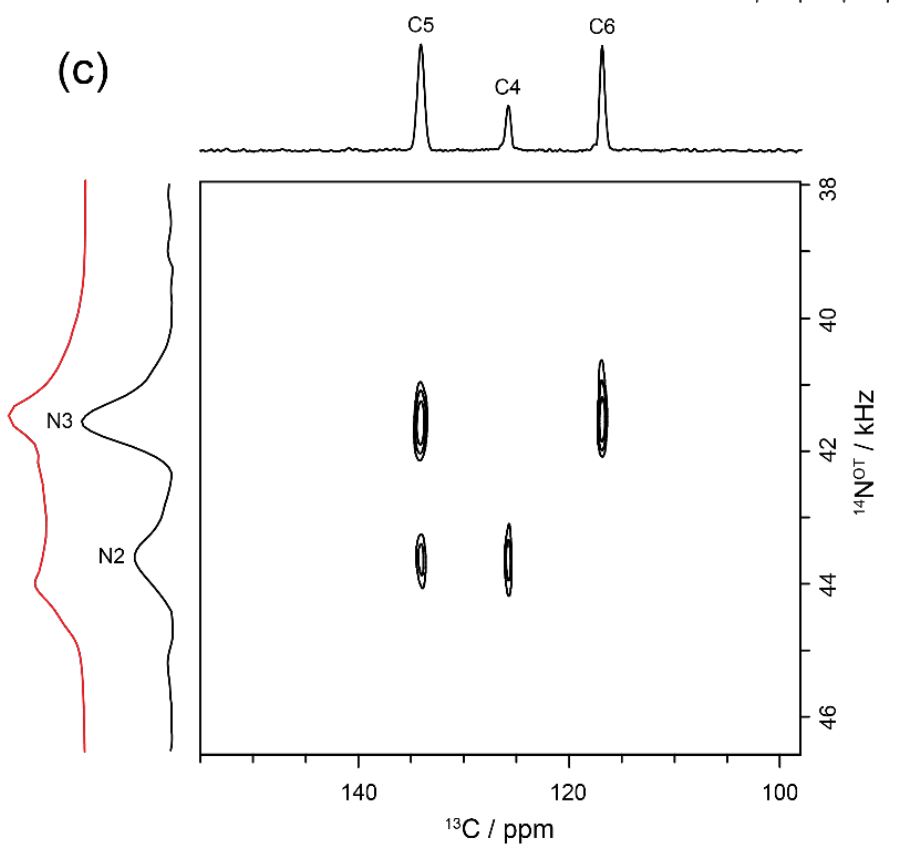

(d)
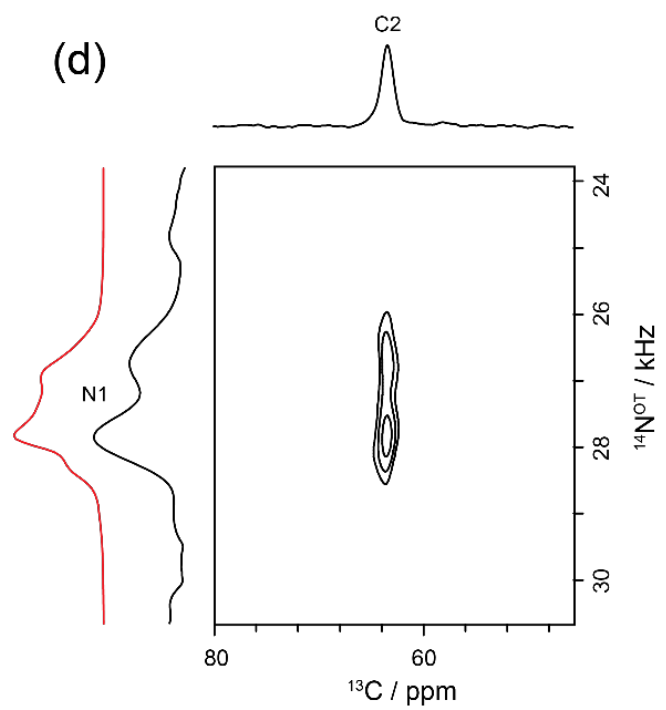

Figure 8 - (a) The L-histidine molecule with sites labelled in accordance to the crystal structure of histidine hydrochloride monohydrate [46]. (b) A DNP-enhanced ${ }^{1} \mathrm{H}_{-1}{ }^{14} \mathrm{~N}^{\mathrm{OT}}$ HETCOR spectrum obtained from histidine $\bullet \mathrm{HCl} \bullet \mathrm{H}_{2} \mathrm{O}$ at $9.4 \mathrm{~T}, 107 \mathrm{~K}$ and $10 \mathrm{kHz}$ MAS (12 scans per slice, 80 slices, $30 \mathrm{~s}$ recycle delay). Horizontal slices through the three ${ }^{14} \mathrm{~N}^{0 T}$ signals are shown to the right, scaled vertically as indicated. ${ }^{1} \mathrm{H}$ chemical shifts were corrected by applying a scaling factor of 0.57 to the indirect dimension spectral width. DNP-enhanced ${ }^{13} \mathrm{C}_{-14} \mathrm{~N}^{\mathrm{OT}} \mathrm{HMQC}$ spectra acquired from the same sample and also at $9.4 \mathrm{~T}, 107 \mathrm{~K}$ and $10 \mathrm{kHz}$ MAS are shown in (c) and (d) with the ${ }^{14} \mathrm{~N}^{\text {TT }}$ pulses applied at approximately $41 \mathrm{kHz}$ and $27 \mathrm{kHz}$ respectively (16 scans per slice, 72 slices, $12 \mathrm{~s}$ recycle delay). 


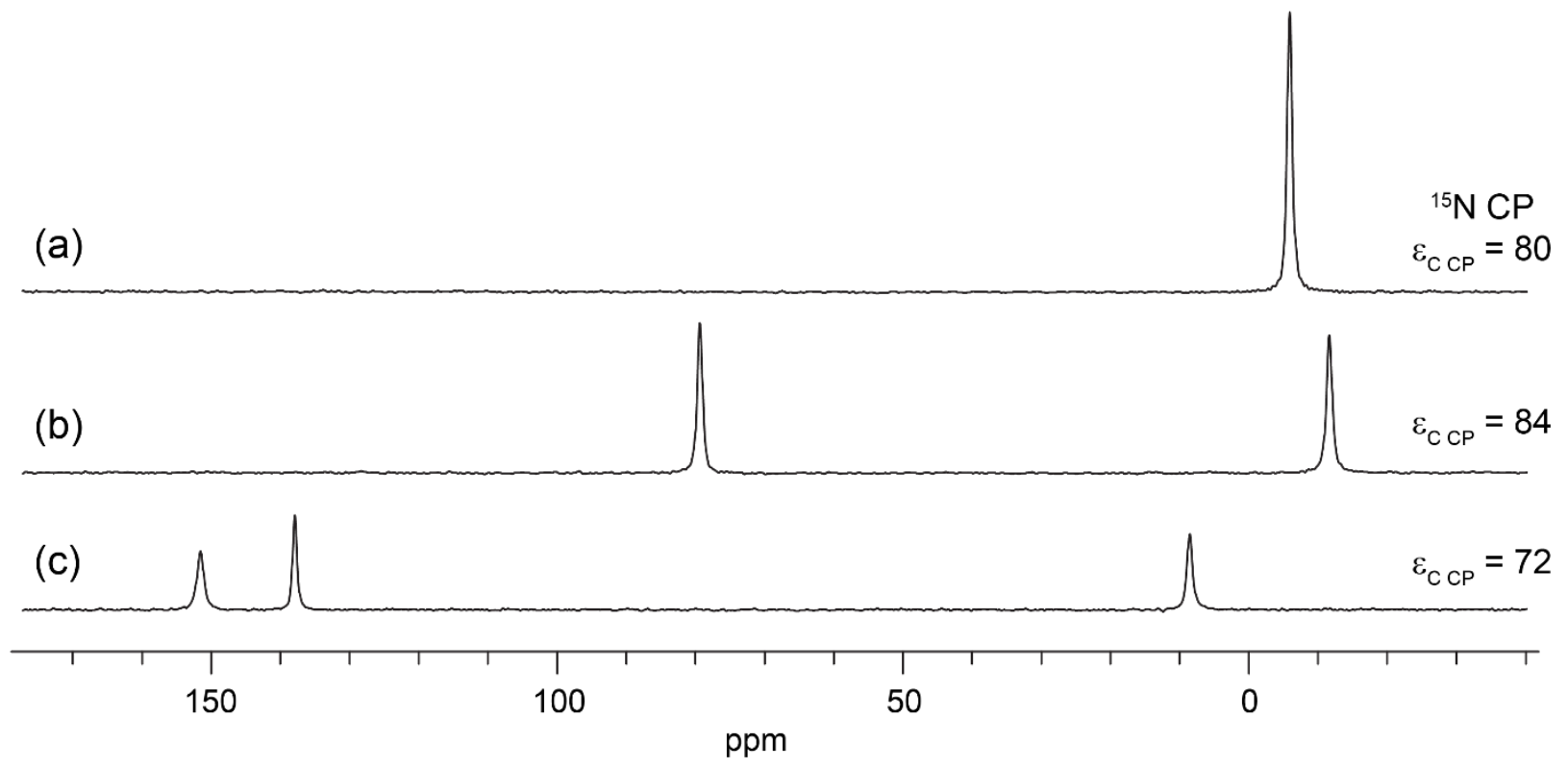

Figure 9 - DNP-enhanced natural abundance ${ }^{15} \mathrm{~N}$ CPMAS spectra obtained from samples of (a) glycine, (b) glycylglycine and (c) histidine $\bullet \mathrm{HCl} \bullet \mathrm{H}_{2} \mathrm{O}$ at $9.4 \mathrm{~T}, 107 \mathrm{~K}$ and $8 \mathrm{kHz} \mathrm{MAS}$. All spectra were acquired in 8 scans with a 60 s recycle delay and a contact time of $8 \mathrm{~ms}$. The chemical shift scale is referenced to solid $\mathrm{NH}_{4} \mathrm{Cl}$ for consistency with the ${ }^{14} \mathrm{~N}^{\text {OT }}$ spectra. All spectra were apodized with $10 \mathrm{~Hz}$ of exponential line broadening. 


\title{
Dynamic nuclear polarisation enhanced \\ ${ }^{14} \mathrm{~N}$ overtone MAS NMR spectroscopy: \\ Supporting information
}

\author{
Aaron J. Rossini, ${ }^{a}$ Lyndon Emsley a and Luke A. O'Dell ${ }^{b *}$, \\ ${ }^{a}$ Centre de RMN à Trés Hauts Champs, Institut de Sciences Analytiques, Université de Lyon \\ (CNRS/ENS Lyon/UCB Lyon 1), 69100 Villeurbanne, France \\ bInstitute for Frontier Materials, Deakin University, Waurn Ponds Campus, Geelong, Victoria 3220, \\ Australia
}

*Corresponding author: luke.odell@deakin.edu.au

S1. ${ }^{14} \mathrm{~N}$ NMR parameters used in the simulations

S2. Glycine ${ }^{13} \mathrm{C}$ CP DNP enhancement

S3. Glycine ${ }^{14} \mathrm{~N}^{\mathrm{OT}} \mathrm{CP}$ on resonance with $+2 \omega_{\mathrm{r}}$ and $+\omega_{\mathrm{r}}$ overtone sidebands

S4. Glycylglycine ${ }^{13} \mathrm{C}$ CP DNP enhancement

S5. Simulations modelling the effect of the contact time on the ${ }^{14} \mathrm{~N}^{\mathrm{OT}}$ powder pattern

S6. Histidine. $\mathrm{HCl} . \mathrm{H}_{2} \mathrm{O}{ }^{13} \mathrm{C}$ CP DNP enhancement

S7. Quantification of ${ }^{13} \mathrm{C}_{-14} \mathrm{~N}^{\mathrm{OT}} \mathrm{HMQC}$ coherence transfer efficiency

S8. Comparison of ${ }^{14} \mathrm{~N}^{\mathrm{OT}}$ and ${ }^{15} \mathrm{~N}$ sensitivities 
S1. ${ }^{14} \mathrm{~N}$ NMR parameters used in the simulations

\begin{tabular}{ccccc} 
Sample & Site & $\mathbf{C}_{\mathrm{Q}} / \mathbf{M H z}$ & $\eta_{\mathrm{Q}}$ & $\boldsymbol{\delta}_{\text {iso }}\left({ }^{15} \mathbf{N}\right) / \mathbf{p p m}$ \\
\hline \hline Glycine & $\mathrm{N} 1$ & 1.18 & 0.53 & -6 \\
\hline Glycylglycine & $\mathrm{N} 1$ & 1.40 & 0.10 & -12 \\
& $\mathrm{~N} 2$ & 3.29 & 0.45 & 79 \\
\hline \multirow{2}{*}{ Histidine.HCl. $\mathrm{H}_{2} \mathrm{O}$} & $\mathrm{N} 1$ & 1.25 & 0.35 & 8 \\
& $\mathrm{~N} 2$ & 1.52 & 0.25 & 138 \\
& $\mathrm{~N} 3$ & 1.21 & 0.94 & 152
\end{tabular}

Table S1 - NMR parameters used to simulate the ${ }^{14} \mathrm{~N}^{\text {OT }}$ MAS spectra of the various sites for the three samples studied. The isotropic chemical shifts $\delta_{\text {iso, }}$ which determine the position of the ${ }^{14} \mathrm{~N}^{\text {OT }}$ powder patterns, were measured from the ${ }^{15} \mathrm{~N}$ CPMAS spectra and were fixed in the ${ }^{14} \mathrm{~N}^{\text {OT }}$ simulations. The quadrupolar parameters $C_{Q}$ and $\eta_{0}$, which determine the shape and width of the powder patterns, were adjusted to match the simulated spectra to the experimental ${ }^{14} \mathrm{~N}^{\mathrm{OT}}$ data, using values calculated from density functional theory as initial guesses. 


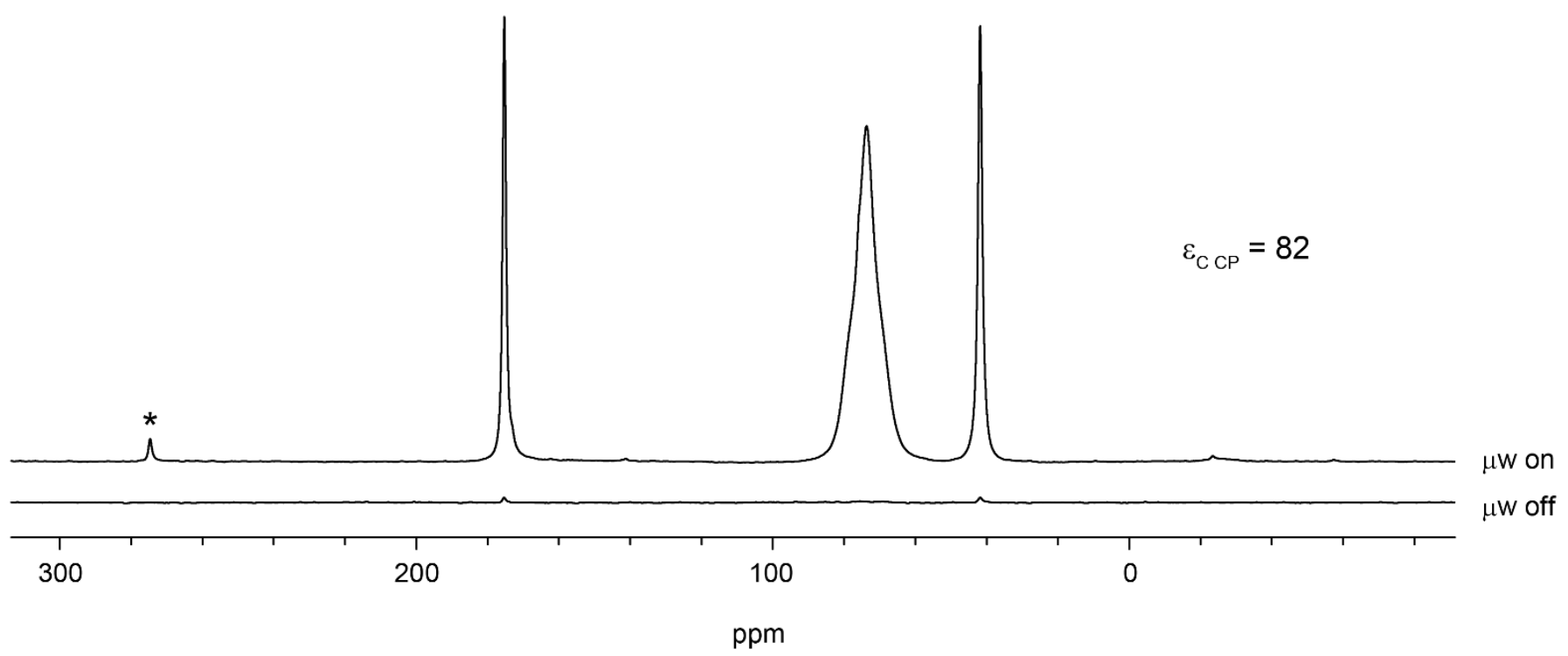

Figure S2 ${ }^{13} \mathrm{C}$ CPMAS NMR spectra obtained from a solid powder sample of glycine impregnated with a solution of TEKPol in tetrachloroethane, with and without $70 \mathrm{~mA}$ microwave irradiation applied. The spectra were obtained at $9.4 \mathrm{~T}, 107 \mathrm{~K}$ and $10 \mathrm{kHz}$ MAS (4 scans with $10 \mathrm{~s}$ recycle delay and $2 \mathrm{~ms}$ cross-polarisation contact time). Asterisks denote spinning sidebands. The ${ }^{13} \mathrm{C}$ signal from the TCE is visible at $74 \mathrm{ppm}$. 
S3. Glycine ${ }^{14} N^{\text {OT }}$ CP on resonance with $+2 \omega_{r}$ and $+\omega_{r}$ overtone sidebands

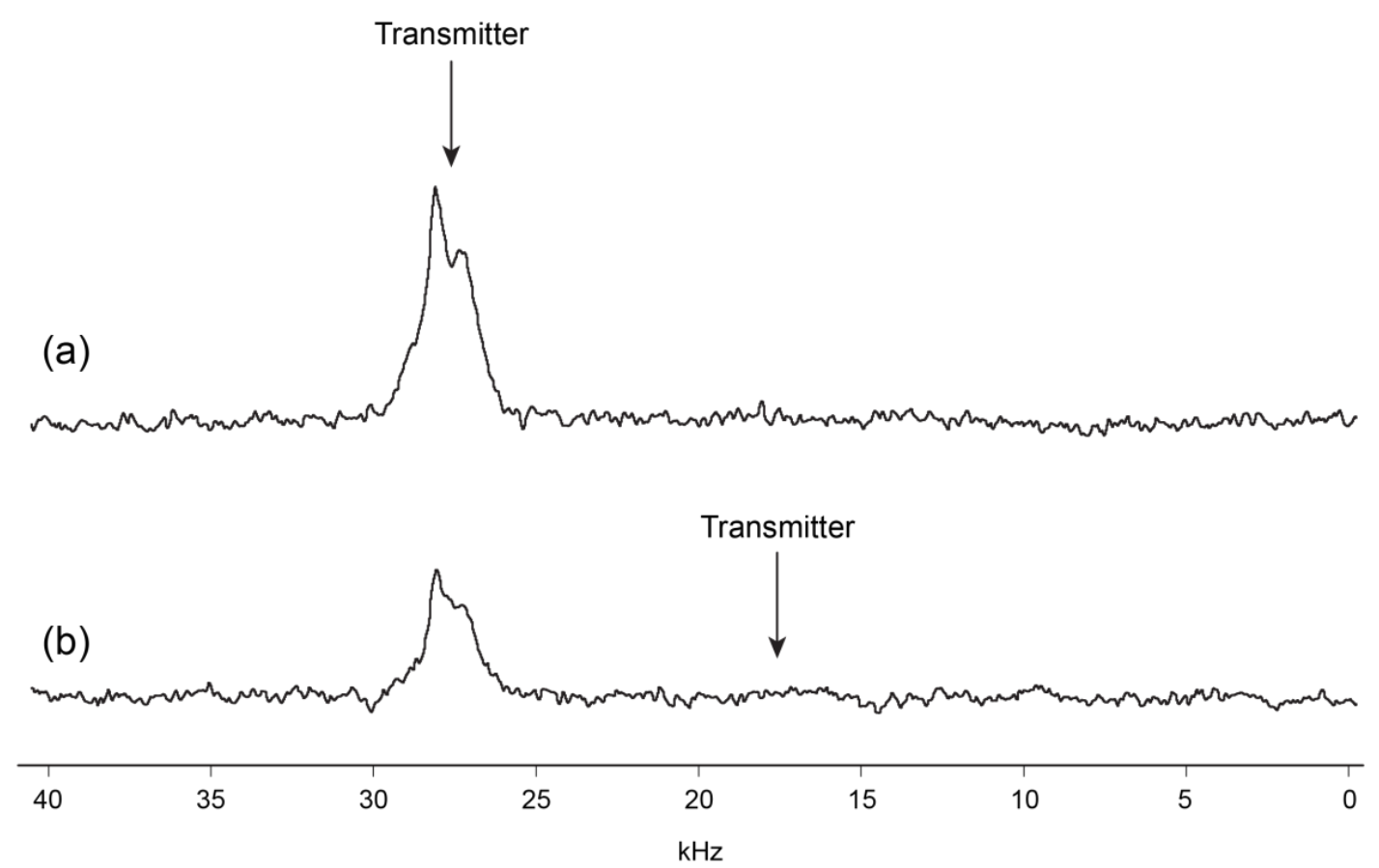

Figure S3 - DNP-enhanced ${ }^{14} \mathrm{~N}^{\text {OT }}$ CPMAS spectra obtained from a solid powder sample of glycine impregnated with a solution of TEKPol in tetrachloroethane, at 9.4 T and $107 \mathrm{~K}$. Both spectra were obtained at $10 \mathrm{kHz}$ MAS with a CP contact time of $125 \mu \mathrm{s}, 16$ scans and a recycle delay of $40 \mathrm{~s}$. In spectrum (a) the ${ }^{14} \mathrm{~N}^{\text {OT }}$ transmitter frequency was placed on resonance with the $+2 \omega_{\text {r }}$ overtone sideband as shown. In (b) this frequency was adjusted by $-10 \mathrm{kHz}$, but no $+\omega_{\mathrm{r}}$ overtone sideband was observed. 


\section{S4. Glycylglycine ${ }^{13} \mathrm{C}$ CP DNP enhancement}

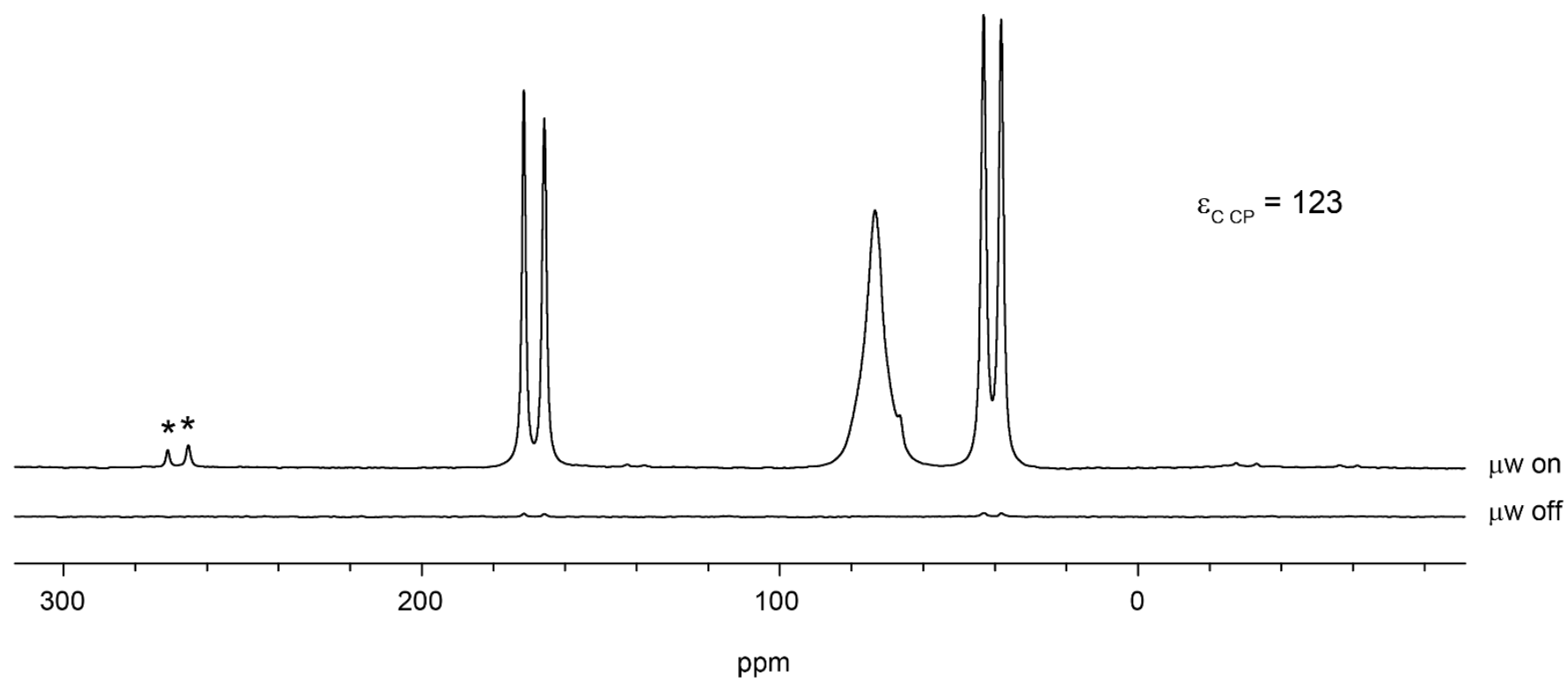

Figure S4 $-{ }^{13}$ C CPMAS NMR spectra obtained from a solid powder sample of glycylglycine impregnated with a solution of TEKPol in tetrachloroethane, with and without $70 \mathrm{~mA}$ microwave irradiation applied. The spectra were obtained at $9.4 \mathrm{~T}, 107 \mathrm{~K}$ and $10 \mathrm{kHz}$ MAS (4 scans with $10 \mathrm{~s}$ recycle delay and $2 \mathrm{~ms}$ cross-polarisation contact time for ${ }^{13} \mathrm{C}$ ). Asterisks denote spinning sidebands, and the ${ }^{13} \mathrm{C}$ signal from the TCE is visible in at $74 \mathrm{ppm}$. 
S5. Simulations modelling the effect of the contact time on the ${ }^{14} \mathrm{~N}^{\text {OT }}$ powder pattern

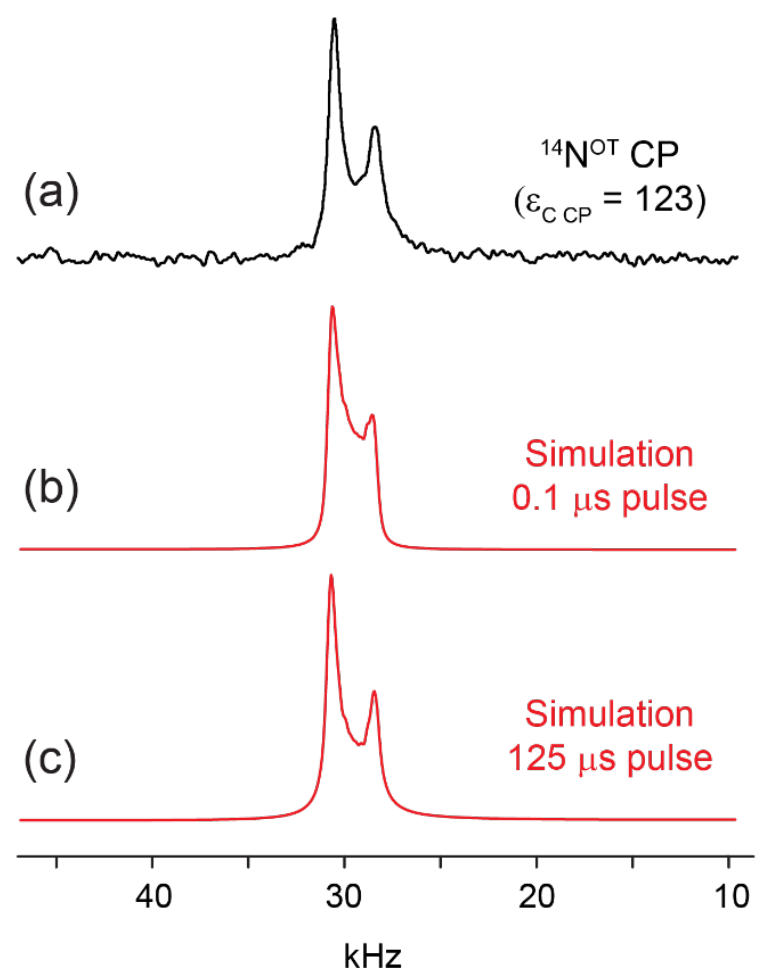

Figure $\mathrm{S} 5-\left(\right.$ a) ${ }^{14} \mathrm{~N}^{\mathrm{OT}}$ spectrum obtained from glycylglycine at $107 \mathrm{~K}, 9.4 \mathrm{~T}$ and $10 \mathrm{kHz} \mathrm{MAS}$ using DNP-enhanced cross-polarisation from the ${ }^{1} \mathrm{H}$ nuclei, with a CP contact time of $125 \mu$ s and the ${ }^{14} \mathrm{~N}^{\mathrm{OT}}$ contact pulse applied on resonance with the $\mathrm{N} 1$ peak at $30 \mathrm{kHz}$. 20 scans were acquired with a recycle delay of $40 \mathrm{~s}$. Simulations made using pulse lengths of (b) $0.1 \mu \mathrm{s}$ and (c) $125 \mu \mathrm{s}$ are also shown to model the effects of the contact time on the powder pattern shape. 


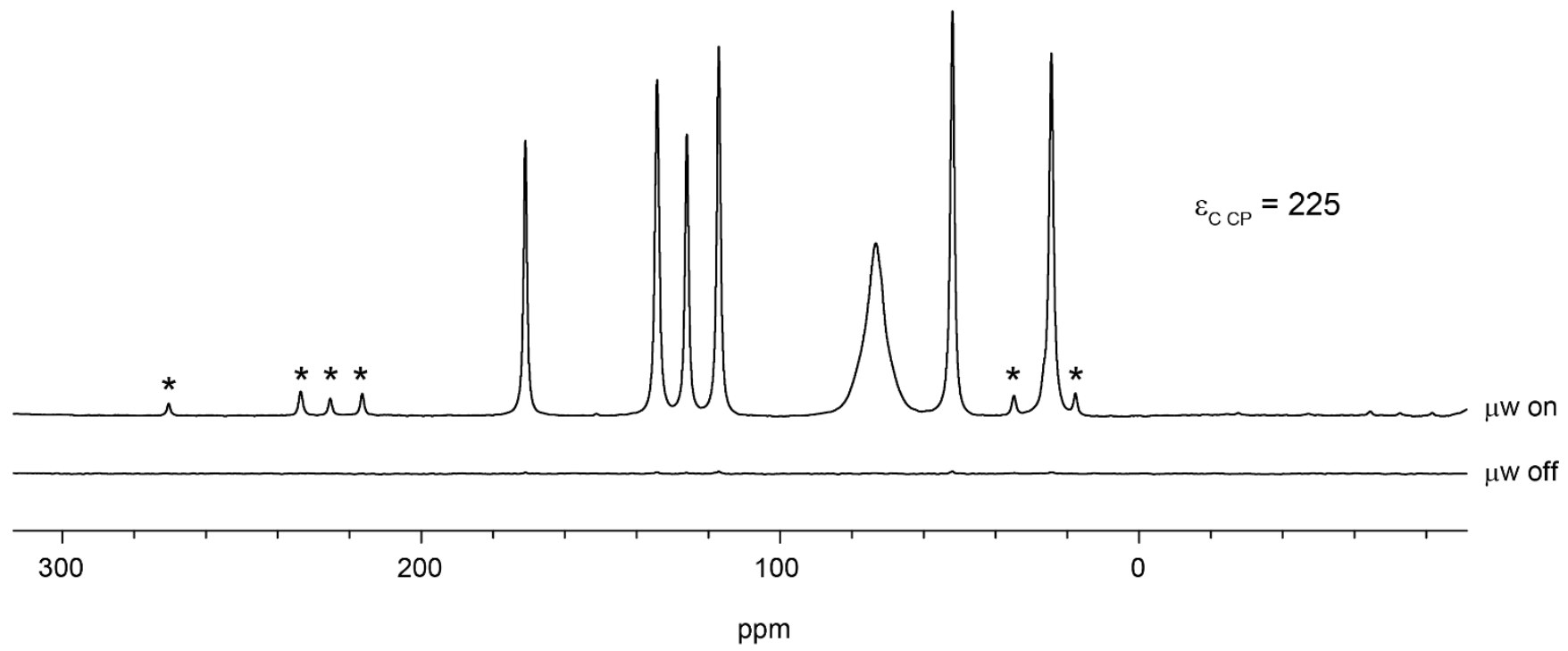

Figure S6 - ${ }^{13} \mathrm{C}$ CPMAS NMR spectra obtained from a solid powder sample of histidine. $\mathrm{HCl} . \mathrm{H}_{2} \mathrm{O}$ impregnated with a solution of TEKPol in tetrachloroethane, with and without $70 \mathrm{~mA}$ microwave irradiation applied. The spectra were obtained at $9.4 \mathrm{~T}, 107 \mathrm{~K}$ and $10 \mathrm{kHz}$ MAS (4 scans with $10 \mathrm{~s}$ recycle delay and 2 ms cross-polarisation contact time for ${ }^{13} \mathrm{C}$ ). Asterisks denote spinning sidebands, and the ${ }^{13} \mathrm{C}$ signal from the TCE is visible in at $74 \mathrm{ppm}$. 
S7. Efficiency of ${ }^{13} \mathrm{C}_{-}{ }^{14} \mathrm{~N}^{\text {OT }} \mathrm{HMQC}$ filters

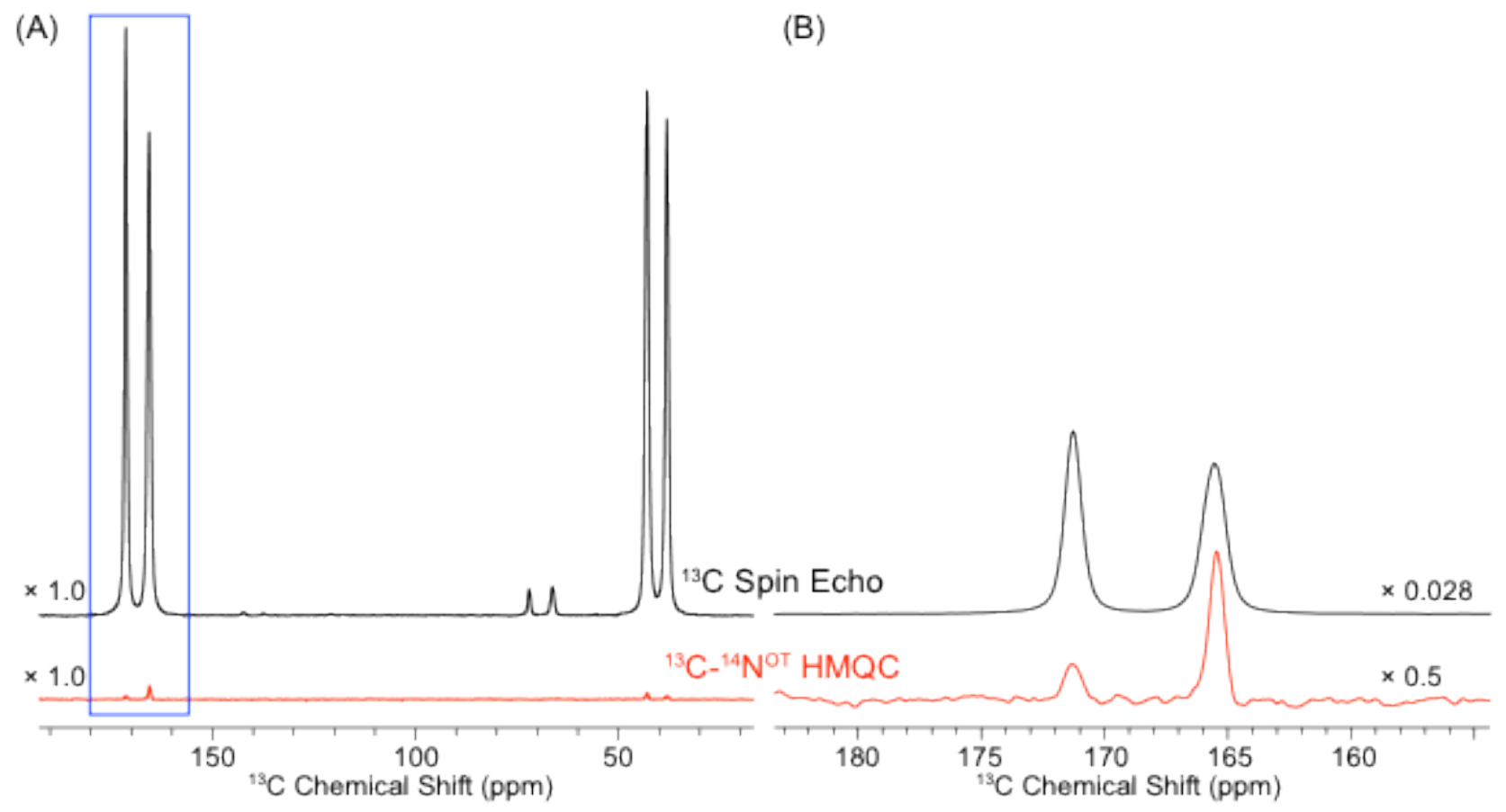

Figure S7 - Comparison of DNP enhanced ${ }^{1} \mathrm{H}-{ }^{13} \mathrm{C} C P$ spin echo spectrum (16 scans) and ${ }^{1} \mathrm{H}_{-}{ }^{13} \mathrm{C} \mathrm{CP}$ HMQC ${ }^{14} \mathrm{~N}^{\text {OT }}$ filtered spectrum (32 scans) acquired with a $200 \mu \mathrm{s}{ }^{14} \mathrm{~N}^{\text {OT }} 90^{\circ}$ pulse applied on resonance with the amide $(-\mathrm{NH})$ nitrogen for coherence transfer. In both cases the total ${ }^{13} \mathrm{C}$ transverse magnetization evolution time was $15 \mathrm{~ms}$. The efficiency of the ${ }^{14} \mathrm{NOT}$ HMQC filter is $2.8 \%$. In both cases a $10 \mathrm{~s}$ recycle delay was employed. 
S8. Comparison of ${ }^{14} \mathrm{~N}^{\text {OT }}$ and ${ }^{15} \mathrm{~N}$ sensitivities

\begin{tabular}{|c|c|c|c|c|c|c|c|c|c|c|c|}
\hline \multirow[b]{2}{*}{ Sample } & \multirow[b]{2}{*}{ Site } & \multicolumn{2}{|c|}{ Number of scans } & \multicolumn{2}{|c|}{ Experiment time / min } & \multicolumn{2}{|c|}{ Line width / Hz } & \multicolumn{2}{|c|}{$S / N$} & \multicolumn{2}{|c|}{$\varepsilon_{\mathrm{CCP}}$} \\
\hline & & ${ }^{14} \mathbf{N}^{\mathrm{OT}}$ & ${ }^{15} \mathrm{~N}$ & ${ }^{14} \mathrm{~N}^{\mathrm{OT}}$ & ${ }^{15} \mathrm{~N}$ & ${ }^{14} N^{O T}$ & ${ }^{15} \mathrm{~N}$ & ${ }^{14} \mathrm{~N}^{\text {OT }}$ & ${ }^{15} \mathrm{~N}$ & ${ }^{14} \mathrm{~N}^{\text {OT }}$ & ${ }^{15} \mathrm{~N}$ \\
\hline Glycine & N1 & 16 & 8 & 11 & 8 & 1500 & 34 & 34 & 291 & 82 & 80 \\
\hline \multirow{2}{*}{ Glycylglycine } & $\mathrm{N} 1$ & 32 & \multirow{2}{*}{8} & 32 & \multirow{2}{*}{8} & 3000 & 36 & 33 & 140 & \multirow{2}{*}{123} & \multirow{2}{*}{84} \\
\hline & N2 & 32 & & 32 & & 8500 & 34 & 13 & 153 & & \\
\hline \multirow{3}{*}{ Histidine. $\mathrm{HCl} . \mathrm{H}_{2} \mathrm{O}$} & $\mathrm{N} 1$ & \multirow{3}{*}{64} & \multirow{3}{*}{8} & \multirow{3}{*}{64} & \multirow{3}{*}{8} & 2000 & 35 & 19 & 78 & \multirow{3}{*}{225} & \multirow{3}{*}{72} \\
\hline & N2 & & & & & 4000 & 28 & 15 & 98 & & \\
\hline & N3 & & & & & 1500 & 50 & 25 & 60 & & \\
\hline
\end{tabular}

Table S2 - Comparison of factors contributing to ${ }^{14} \mathrm{~N}^{\mathrm{OT}}$ and ${ }^{15} \mathrm{~N}$ sensitivities in the directly-observed, DNP-enhanced spectra acquired in this work.

Other experimental details can be found in the main article. All spectra were acquired at $9.4 \mathrm{~T}$ and a temperature of around $107 \mathrm{~K}$. 